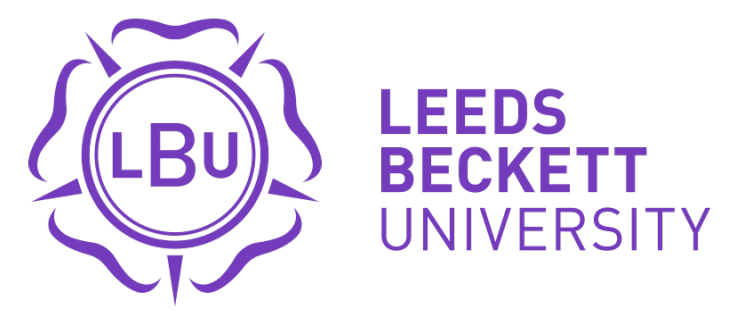

Citation:

Thampanya, $\mathrm{N}$ and $\mathrm{Wu}, \mathrm{J}$ and Nasir, MA and Liu, J (2020) Fundamental and behavioural determinants of stock return volatility in ASEAN-5 countries. Journal of International Financial Markets, Institutions and Money, 65. ISSN 1042-4431 DOI: https://doi.org/10.1016/j.intfin.2020.101193

Link to Leeds Beckett Repository record:

https://eprints.leedsbeckett.ac.uk/id/eprint/6601/

Document Version:

Article (Accepted Version)

Creative Commons: Attribution-Noncommercial-No Derivative Works 4.0

The aim of the Leeds Beckett Repository is to provide open access to our research, as required by funder policies and permitted by publishers and copyright law.

The Leeds Beckett repository holds a wide range of publications, each of which has been checked for copyright and the relevant embargo period has been applied by the Research Services team.

We operate on a standard take-down policy. If you are the author or publisher of an output and you would like it removed from the repository, please contact us and we will investigate on a case-by-case basis.

Each thesis in the repository has been cleared where necessary by the author for third party copyright. If you would like a thesis to be removed from the repository or believe there is an issue with copyright, please contact us on openaccess@leedsbeckett.ac.uk and we will investigate on a case-by-case basis. 


\title{
Fundamental and behavioural determinants of stock return volatility in ASEAN-5 countries
}

\author{
Natthinee Thampanya ${ }^{1}$, Junjie $\mathrm{Wu}^{2 *}$, Muhammad Ali Nasir ${ }^{3}$, Jia $\mathrm{Liu}^{4}$ \\ ${ }^{1}$ Faculty of Business, Economics and Communications, Naresuan University, Thailand \\ ${ }^{2,3}$ Leeds Business School, Leeds Beckett University, UK \\ ${ }^{4}$ Salford Business School, University of Salford. UK
}

\begin{abstract}
Fundamental and behavioural factors are the two determinants of stock prices but are rarely investigated simultaneously. This paper examines the role of fundamental and behavioural factors in stock return volatility in the Association of Southeast Asian Nations-5 countries (ASEAN-5) for the period of January 1995 to December 2018 comprising three regimes (before Asian, between Asian and Global, and after Global financial crises). We find that fundamental factors play crucial roles in influencing stock market volatility in Malaysia, Thailand, and Singapore; whereas, behavioural factors affect stock market volatility more significantly than fundamental factors in Indonesia and the Philippines. We find distinctive differences across the three regimes supporting the above findings. Further our results suggest that ASEAN-5 has made encouraging progress of integration with Malaysia and Thailand being closer to Singapore in terms of economic development, corporate values, and political stability; however, Indonesia and the Philippines are much behind showing economic instability and their vulnerabilities are especially associated with the timing of the Asian and global financial crises. Our findings also suggest that monetary policies play a more important role than fiscal policies in the region and highlight a number of policy implications.
\end{abstract}

Keywords: Fundamental Factors; Behavioural Factors; Stock Return Volatility; EGARCH model; ARDL model; ASEAN-5.

\section{Introduction}


Fundamental factors are derived from conventional finance theory on the assumption that investors follow basic financial rules and design investment strategies purely based on the riskreturn consideration (Baker et al., 1977). Fundamentally different from rational expectation hypothesis, behavioural finance asserts that investors are ordinary people influenced by sentiment and psychological prejudices, that markets are inefficient, and that differences in expected returns are decided by more than the differences in risk (Statman, 2014). Behavioural factors better explain the observation of stock markets that many investors make decisions following good/bad news, or other factors, e.g. herding, loss aversion. These 'noise' traders make stock markets informationally inefficient, and this leaves arbitrage pricing theory (the cornerstone of conventional finance) with a limited role to play (De Long et al., 1990; Shleifer and Summers, 1990). Therefore, fundamental value and sentiment are the two driving forces of stock price movements. Stock prices reflect actual value only when markets are efficient and traders have full information; however, in real-world, irrational noise traders play a crucial part in influencing stock prices and sometimes their roles are even more significant than the latter (Fisher and Statman, 2000, 2004). As pointed out by Subrahmanyam (2007), "The evidence in favour of inefficient financial markets is far more compelling than that in favour of efficient markets" (cited in French, 2017, p. 129).

Studies of fundamental and behavioural factors are often conducted separately in either developed or emerging markets, with more studies of fundamental factors linked to developed markets, while more behavioural studies are found for emerging markets (Baker and Wurgler, 2006). Emerging and developed markets have distinctive characteristics in terms of types of financial products, the extent of risk-return and volatilities, and financial certainty/uncertainty (Kumari and Mahakud, 2015). Arguably, a study that investigates how fundamental and behavioural factors influence decisions in a regional stock market that includes both developed and emerging countries would enhance our knowledge as to how the market work, which will stimulate further research. This is because such a study can capture the natures of how these two types of factors would interact in the regional market and its integration of this market.

We argue that the stock markets of the Association of Southeast Asian Nations (ASEAN) are an appropriate location for such a study. First, the Southeast Asia region, which comprises five original member countries, namely Singapore, Malaysia, Indonesia, the Philippines and Thailand, has experienced rapid economic growth for decades. Investors tend to seek higher returns from stock markets in this region, which are subject to high volatilities in the meantime. These features thus provide an ideal case for examining the impact of macroeconomic and 
corporate factors (i.e. fundamental factors). Second, the Southeast Asian stock markets are more speculative than other developed regional markets such as those in the US and Europe (Lu et al., 2018); hence, there is a greater prevalence of noise traders in this regional market, which provides us with an opportunity for assessing the influence of behavioural factors. Third, the ASEAN-5 contains both developed and developing markets ${ }^{1}$, with Singapore well known to be a developed (though small) market, while the other four are generally recognised to be emerging markets. Given these features, it would be possible to explore what roles fundamental and behavioural factors play in the regional market. Finally, and most importantly, the ASEAN region has been undergoing integration and a significant number of studies have discussed the extent to which this has been achieved. For example, Click and Plummer (2005) examine stock market integration in ASEAN-5 after the 1997 Asian financial crisis using time series cointegration technique and conclude ASEAN-5 are integrated to some extent in the economic term. Similarly, using stock indices, Goh et al. (2005) investigate the intertemporal linkages of the ASEAN-5 responding to 1997 Asian financial crisis and suggest that ASEAN-5 experienced a structural change after mid-1997, while Indonesia led the movements. Lim (2009) also look at whether ASEAN-5 stock markets have correlations and long-run relationships between 1990 and 2008 and reveal signs of converging and integration after the 1997 Asian financial crisis. Truchis and Keddad (2013) find ASEAN-5's monetary integration by examining generalised purchasing power parity and support further monetary integration as ASEAN-5 share long-term co-movements. These studies explore the stock market integration of ASEAN-5 from different angles; however, none of them is done from the perspective of how fundamental and behavioural factors influence stock return volatility. Thus, our investigation, which investigates the two factors in one study, will add a new dimension and fresh evidence to the integration debate; if they behave in a similar way across all sub-group countries in long-run, it suggests that the degree of the regional market integration is high; conversely, the integration level is low.

Our research examines fundamental and behavioural determinants of stock return volatility in ASEAN-5, including Indonesia (Jakarta Stock Exchange Composite Index: JKSE); Malaysia (Kuala Lumpur Stock Exchange Composite Index: KLSE); the Philippines (The Philippine

\footnotetext{
${ }^{1}$ According to the International Monetary Fund (IMF)'s estimation in April 2018, GDP per capita (USD) for ASEAN-5 for 2018 would be 98,014 for Singapore, 30,857 for Malaysia, 18,943 for Thailand, 13,162 for Indonesia, and 8,893 for the Philippines (IMF, 2018). One can see that Singapore is a clear leader in terms of economic development (though its population only counts for $1.18 \%$ in ASEAN-5) ahead of the other four which are middle, low-income emerging economies.
} 
Stock Exchange Index: PSE); the Thailand (Stock Exchange of Thailand Index: SET); and the Singapore (Straits Times Index: STI). We examine monthly data covering the periods from January 1995 to December 2018 (24 years). This extensive period includes the Asian Financial Crisis of 1997/98 and the Global Financial Crisis of 2008/09. In order to capture the specific feature, we examine market volatility across three sub-periods: Regime I (from January 1995 to December 1997), Regime II (from January 1998 to June 2008), and Regime III (from July 2008 to December 2018) based on the structural breaks in the Unit Root tests. We adopt an Exponential Generalised Autoregressive Conditional Heteroskedasticity (EGARCH) model to estimate the magnitude of return volatility, and an Autoregressive Distributed Lag (ARDL) model to examine the short-run dynamics and long-run relationship between the variables. Our findings reveal that the fundamental factors affect stock market volatility more significantly in Malaysia, Thailand, and Singapore than in Indonesia and the Philippines; while behavioural factors, conversely, affect stock market volatility considerably more in Indonesia and the Philippines than in Malaysia, Thailand, and Singapore. The results demonstrate that Malaysia and Thailand have greater similarities to Singapore, whereas the opposite is true in the case of Indonesia and the Philippines. Arguably, this is because Malaysia and Thailand are more integrated with Singapore and become more developed emerging (also called 'catch-up') stock markets; while Indonesia and the Philippines are not integrated to the same degree.

This paper makes three contributions to the existing literature. First, unlike other studies, which examine the impact of either fundamental or behavioural factors on stock return volatility in a single market (either a developed or developing country), we combine the two types of determinants in a regional market - the ASEAN-5 - including both developed and emerging countries. This novel perspective captures how, and to what extent, the two factors affect stock return volatilities in this regional market. Moreover, our data spans 24 years and incorporates both the Asian and global financial crises divided into three Regimes. We identify distinctive differences across the three regimes, i.e. fundamental factors are stable and associated with Malaysia, Thailand and Singapore across all Regimes; however, behavioural factors are linked to Indonesia and the Philippines showing inconsistent across three Regimes, which gives the assurance of our main finding. Second, our findings also offer fresh evidence to support arguments for the integration progress of the ASEAN-5, with the reasons behind this assessment being contextually discussed. Third, our findings shed light on the importance of the region's financial policy on the market movements. In particular, monetary policies play a more critical role than fiscal policies in the region. 
The remainder of this paper is organised as follows: Section 2 reviews the literature and formulates the hypotheses; Section 3 introduces methodological issues; Section 4 presents and discusses the empirical results; Section 5 contextualises discussions; and Section 6 states our conclusions.

\section{Literature review and hypothesis development}

\section{Fundamental factors}

Conventional (neoclassical) finance asserts that stock market participants are rational investors (information traders) who seek maximum wealth by considering fundamental factors (e.g. macroeconomic indicators and financial ratios) and companies' intrinsic values (Baker et al., 1977). Even though some noise traders make decisions based on good/bad news, or engage in herding, they are irrelevant to the stock price, as rational majority traders can drive the price back to equilibrium in the long run (Friedman, 1953; Kumari and Mahakud 2015). In this case, the market is supposed to be efficient.

Macroeconomic indicators, such as GDP, money supply, interest rate, inflation rate and exchange rate, are considered as the fundamentals that drive market movements, and each of these variables is perceived to be unbiased (Francis and Soffer, 1997). On the other hand, scholars argue that a firms' accounting information representing company value, such as revenue, earnings, assets, liabilities, and growth, also determine the fair (intrinsic) value of a stock. Numerous academic papers support the argument that changes in stock return volatility are primarily due to fundamental cash flows and the book-to-market factor (e.g. Gaspar and Massa, 2006; Guo and Savickas, 2008) and also to some financial ratios, such as return-onassets and return-on-equity, and their volatilities (Chang and Dong, 2006). As such, fundamental factors comprise both macroeconomic and corporate variables.

It is assumed that market participants who make investment decisions by considering macroeconomic and corporate fundamentals as rational wealth-maximisers. Macroeconomic indicators largely reflect the economic condition, and thus economic variables have systematic effects on stock market returns through their influence on discount rates, firms' abilities to generate cash flows, and future dividends, and measure risk premiums and their significance to stock market returns (Maysami and Koh, 2000). Corporate variables identified by Fama and French $(1992,2015)$ in their three-factor and five-factor models are widely used for pricing 
stock. A large number of researches provide evidence to support the significant impacts of corporate variables on stock return volatility in comparison to other factors. For example, Bekaert et al. (2012) argue that, amongst three groups of explanatory variables (index composition, corporate variables, and business cycle variables), the most critical determinants of aggregate idiosyncratic volatility are corporate variables.

Ample empirical evidence finds that the significant impact of macroeconomic variables on stock market volatility affects not only developed markets but more developed emerging markets (see Gregoriou, 2009; Konrad, 2009; Gospodinov and Jamali, 2012; Mittnik et al., 2015), while less effect is made on emerging markets (Sharma and Wongbangpo, 2002; Zare et al., 2013). Among others, for example, Chen et al. (1986) examine relationship between economic forces and the stock market in the US; Poon and Taylor (1991) assess the impact of macroeconomic factors in the UK's stock market, and Chang and Dong (2006) derive evidence of the influence of fundamentals from the Japanese stock market. This is because fundamental factors relate directly to the economic condition and financial valuation of a company or security, while developed countries have stable economies, established financial market systems and regulations, and more mature companies. Other more developed emerging countries (i.e. catch-up emerging countries) have made considerable progress in catching up developed countries in recent decades and they largely share the nature with developed countries in stable economies, comparatively matured financial markets and companies.

Given the foregoing discussion, we accordingly hypothesize the following.

H1: Fundamental factors are more likely to be more significant in affecting return volatility of developed stock markets or more developed emerging markets compared to those of other emerging markets.

\section{Behavioural factors}

Fundamental factors are used to describe a market participant, who makes investment decisions by considering corporate and macroeconomic fundamentals. On the other hand, behavioural/non-fundamental factors are used to describe noise trader, who makes investment decisions without the use of fundamentals (Black, 1986). Although asset pricing theory suggests that multiple macroeconomic factors determine the return and risk of a specific asset/stock, in practice, the argument is weakened to some extent because of the difficulties of making firm valuations across stocks (Corredor et al., 2015). In other words, stocks that are 
hard to value and vulnerable to speculation are subject to sentiment, which acts as a systematic risk factor that affects stock pricing (Kumari and Mahakud, 2015). A large number of researches provide evidence that behavioural factors are the determinants of stock volatilities driven by investors' sentiment conditioned by their belief about future cash flows and investment risks (Baker and Wurgler, 2007). These investors are generally called "noise traders', whose investment decisions are affected by emotions, leading to herding behaviour, overconfidence, self-serving bias, and loss aversion, etc. Noise traders play a significant role when stock prices move away from their intrinsic values (Kumari and Mahakud, 2015) so that the market has the potential to rise or fall rapidly, subject to investors' bullish or bearish predispositions.

Investors' bullish or bearish predispositions reflect on stock trading volumes and stock prices. Selden (1912) points out that the concept of psychology in the stock market is mirrored by the movement of stock prices depending on the mental attitude of market participants and trading. According to Shefrin and Statman's (1994) behavioural capital asset pricing theory, when bullish sentiment dominates the stock market, investors buy more stocks and asset prices will be pushed above their real value; whereas, when bearish sentiment dominates, investors sell or hold stocks and prices are dragged below fundamental value, and the market is in a negative bubble. Both bullish and bearish noise trading can make stock markets more volatile (Baker and Wurgler, 2006, 2007). These highly sentiment-sensitive stocks are found more in developing countries than in developed counties (Baker and Wurgler, 2006).

One explanation for changes in stock returns over time is the change in the composition of stock index. Within which, the age characteristics of firms are found to be an important factor affecting stock return volatility. Scholars investigate a related hypothesis about the relationship between age and risky fundamentals of firms and their significant impact on idiosyncratic risk. Specifically, the increase of new firms with more volatility can be key determinant increasing in stock return volatility. For example, Jovanovic and Rousseau (2001) suggest the idiosyncratic variance was driven by the change of attitude toward buying younger listed firms. Their findings confirm that the increase in the proportion of young firms in the market explained a large fraction of the increase in firm-specific risk during the Internet boom of the late 1990s. Safdar (2000) further argues that the addition of new firms can have a substantial effect on an increase in idiosyncratic risk because these firms are more volatile. This conclusion is shared by the studies of Fama and French (2004), and Wei and Zhang (2006). As such, the 
age of firms, or the proportion of young firms, is regarded a good proxy for the behaviour factors which drive the market movement (Pastor and Veronesi, 2003).

Another behavioural factor is associated with political risk. If a country's political environment is stable, investors will have confidence in their investment, and thus the stock market will perform well and show long-run linearity (Tuyon and Ahmad, 2016). In contrast, political shocks can cause the stock market to overreact or underreact and stock prices to fluctuate strongly (Lim and Hinich, 2005; Ali et al., 2010). An interesting example is that, in recent years, the UK's stock market prices often move upwards and downwards following political news about the possibilities of a soft or hard Brexit intensifying the nation's political drama. Emerging countries usually have lower readings in the UN's Index of Political Stability, compared to those of other developed countries (Liu et al., 2019).

Behavioural factors have inspired more discussions in the context of emerging markets, such as Lu et al. (2018) in China, Kumari and Mahakud (2015) in India, and Bakar and Yi (2016) in Malaysia. However, even in the studies incorporating both developed and developing countries, the evidence shows that the impact of investors' sentiments on stock returns are generally higher in countries with less developed financial markets, giving rise to more herdlike behaviour than the impact of investors' sentiment in countries with a reliable financial market system, with more easy-to-arbitrage and less volatile stocks (see Schmeling, 2009; Corredor et al., 2015). The reasons underlying this conclusion are linked to the limits to arbitrage and the difficulties of firm valuation (Schmeling, 2009). This is because emerging markets have more stocks whose valuations are difficult to arbitrage such as new, small, nonprofitable, no dividend payment, and financial distress firms, and are thus subject to speculation. In addition to the effects of sentiment, country-specific factors, such as the maturity of the stock market, the level of integration with other markets, and the institutional and cultural contexts, could also play roles in determining stock return volatility because of their influences on information quality, the legal system and corporate governance (e.g., Chang et al., 2012).

Based on the above arguments, our corresponding hypothesis is thus the following.

Hypothesis 2: The impact of behavioural factors on stock return volatility is more significant in emerging financial markets than in developed ones. 


\section{Methodological issues}

\subsection{Volatility Estimating with an EGARCH Model}

We adopt the EGARCH model to estimate stock return volatility because it addresses the symmetric restriction of standard GARCH (Nelson, 1991). The asymmetric GARCH model can capture the asymmetric effects of conditional variance on excess return (Jiranyakul, 2011). Concomitantly, the non-negativity constraints on the coefficients in the conditional variance equation are not imposed on the model. The conditional variance equation can be expressed in the following specification:

$$
\log \left(\sigma_{t+1}^{2}\right)=\omega+\alpha\left|\frac{\varepsilon t}{\sigma t}\right|+\gamma \frac{\varepsilon t}{\sigma t}+\beta \log \left(\sigma_{t}^{2}\right)
$$

where $\sigma_{t}^{2}$ is the conditional variance at time $t$; $\omega$ is constant-coefficient; $\alpha$ parameter represents a magnitude effect or the symmetric effect of the model(the "GARCH" effect); $\gamma$ parameter measures the asymmetry or the leverage effect that the EGARCH model allows for testing of asymmetries. If $\gamma=0$, then the model is symmetric. When $\gamma<0$, negative shocks (bad news) generate more volatility than positive shocks (good news). When $\gamma>0$, it implies that positive innovations are more destabilising than negative innovations; $\beta$ measures the persistence in conditional volatility irrespective of anything happening in the market. When $\beta$ is relatively large, volatility takes a long time to diminish.

\section{Diagnostic check}

Once the model has been estimated, a diagnostic check is necessary to investigate whether the model can be accepted for its assumptions. We apply a correlogram-Q-statistics and ARCH LM test for residual diagnostics. Correlogram-Q-statistics displays the correlogram (autocorrelations and partial autocorrelations) of the standardised residuals. This procedure can be used to test for remaining serial correlation in the mean equation and to check the specification of the mean equation. If the mean equation is correctly specified, all Q-statistics should not be significant. In addition, ARCH LM test carries out Lagrange multiplier tests to test whether the standardised residuals exhibit additional ARCH. If the variance equation is correctly specified, there should be no ARCH effects in the standardised residuals. Table 1 shows the results of residual diagnostics in the mean equation of five countries. Table 2 illustrates the results of residual diagnostics invariance equation of five countries.

\section{Insert Table 1 here.}


Table 1 shows that correlogram-Q-statistics display the autocorrelation and partial autocorrelation functions up to the specified order of lags (10 lags). The results for all five countries show that all Q-statistics are not significant at benchmarked 95\% level of confidence, indicating that the mean equations are correctly specified.

\section{Insert Table 2 here.}

Table 2 shows that the ARCH LM test is a test for autoregressive conditional heteroskedasticity $(\mathrm{ARCH})$ in the residuals (Engle, 1982). This heteroskedasticity specification was motivated by the observation that in financial time series, the magnitude of residuals appears to be related to the magnitude of recent residuals. ARCH, in itself, does not invalidate standard least-square inference. However, ignoring ARCH effects may result in loss of efficiency. The ARCH LM test statistic is computed from an auxiliary test regression to test the null hypothesis that there is no ARCH effect. For all the five countries, the results indicate that we can accept the null hypothesis $(\mathrm{P}$-value $>0.05)$ that the residual has no ARCH effect. Therefore, the variance equation is correctly specified.

\subsection{An Autoregressive Distributed Lag (ARDL) Model}

One potential problem with a long-period data set is structural breaks in the observed data. The problem of structural breaks is empirically indistinguishable from the unit root problem in traditional unit root tests, such as when the augmented Dickey-Fuller test (Dickey and Fuller, 1979) is applied. Also, traditional econometric models, such as the Vector Auto-regression model/VAR or co-integration modelling, are unsuitable for addressing the problem of structural breaks because they cannot deal with data with integrals of different orders. Unlike previous studies that directly use VAR or co-integration techniques, we can adopt an ARDL model and bounds testing approach, as suggested by Pesaran et al. (2001). The ARDL model has the advantage of allowing us to deal with data that have integrals of different orders, which are usually observed when a structural break problem occurs. The ARDL approach is also robust for small sample size (Pattichis, 1999; Mah, 2000; Tang and Nair, 2002). The ARDL model can be specified as follows:

$$
y_{t}=\alpha+\sum_{i=1}^{p} \gamma_{i} y_{t-i}+\sum_{j=1}^{k} \sum_{i=0}^{q_{j}} X_{j, t-i}{ }^{\prime} \beta_{j, i}+\varepsilon_{t}
$$


An ARDL is a least-squares (LS) regression containing lags of the dependent and explanatory variables. ARDLs are usually denoted with the notation $\operatorname{ARDL}\left(p, q_{1}, \ldots, q_{k}\right)$, where $p$ is the number of lags of the dependent variable (stock return volatility); $q_{1}$ is the number of lags of the first explanatory variable; and $q_{k}$ is the number of lags of the $k$-th explanatory variable. Some of the explanatory variables may have no lagged terms in the model $\left(q_{j}=0\right)$. These variables are called static or fixed regressors. Explanatory variables with at least one lagged term are called dynamic regressors. In our analysis, past values of stock return volatility, current and previous values of explanatory variables function as dynamic regressors of the current value of stock return volatility.

We adopt Akaike's information criterion (AIC) for lag selection (Liew, 2004). According to Wooldridge (2015), the inclusion of a time trend can highlight a meaningful relationship between $y_{t}$ (dependent variable) and one or more $x$ variables (explanatory variables). If their coefficients are the estimates of their co-movement with $y$, the coefficient of $x$ is the trend in $y$. Therefore, we estimate the ARDL with trend included. We attempt to use the same assumption, a time trend (linear), to specify the models so that we are able to establish comparable models over time and across the countries. However, one equation may not be appropriate for all cases. We run CUSUM and CUSUM of Squares (CUSUMSQ) tests for a diagnostic check and find that the models that we used are stable, except for the Philippines in Regime I. $^{2}$ A further problem is due to the possible instability of the underlying estimated model. As we apply one equation to all cases, the instability arises from the inappropriate assumption of a linear trend in the model. Therefore, we use the ARDL without trend included for Regime I of the Philippines (see Table 6).

\subsection{Bounds Test for Co-Integration}

\section{Long-Run Relationship}

An ARDL model estimates the dynamic relationship between a dependent variable and explanatory variables, and it can be transformed into a long-run representation (Pesaran et al., 2001) as follows:

$$
\theta_{j}=\sum_{i=1}^{j} \beta_{j, i}^{\wedge} / 1-\sum_{i=1}^{p} \gamma_{i}
$$

\footnotetext{
${ }^{2}$ The results of CUSUM and CUSUM of Squares (CUSUMSQ) tests are available upon request.
} 
$\theta_{j}$ is estimated long-run coefficients, indicating the long-run response of the dependent variable to a change in the explanatory variables.

\section{Co-Integrating Relationship}

Traditional methods of estimating co-integrating relationships, such as Engle and Granger (1987) and Johansen (1991, 1995), or single equation methods such as Fully Modified OLS (ordinary least squares) and Dynamic OLS, either require prior knowledge and specifications regarding which variables are $l(0)$ and which are $l(1)$, or for all variables to be $l(1)$. To alleviate this problem, Pesaran and Shin (1999) postulate that the ARDL models can estimate cointegrating systems where the variables can be either $l(0)$ or $l(1)$, without need to pre-specify $l(0)$ or $l(1)$. Pesaran and Shin (1999) also note that unlike other methods of estimating cointegrating relationships, the ARDL representation does not require symmetry of lag length. Thus, each variable can have a different number of lags. The co-integrating regression form of an ARDL model is obtained by transforming Equation (2) into differences and substituting the long-run coefficients from Equation (3) as follows:

$$
\Delta y_{t}=-\sum_{i=1}^{p-1} \gamma_{i *} \Delta y_{t-1}+\sum_{j=1}^{k} \sum_{i=0}^{q_{j-1}} \Delta X_{j, t-i^{\prime}} \beta_{j, i *}-\emptyset^{\wedge} E C_{t-1}+\epsilon_{t}
$$

where

$$
\begin{aligned}
& E C_{t}=y_{t}-\alpha-\sum_{j=1} X_{j, t^{\prime}} \theta^{\wedge}{ }_{j} \\
& \emptyset^{\wedge}=1-\sum_{i=1}^{p} \gamma^{\wedge} \\
& \gamma_{i *}=\sum_{m=i+1}^{p} \gamma_{m}^{\wedge} \\
& \beta_{j, i *}=\sum^{q_{j}} \beta_{j, m}
\end{aligned}
$$

$y_{t}$ is the dependent variable (stock return volatility), where $p$ is the number of lags of the dependent variable; $X_{j}$ is explanatory variables, where $q_{1}$ the number of lags of the first explanatory variable; and $q_{k}$ is the number of lags of the $k$-th explanatory variable; $\varepsilon_{t}$ is the standard error of the cointegrating relationship coefficients and can be calculated from the standard errors of the original regression using the delta method (Pesaran and Shin, 1999). 


\subsection{Granger Causality}

The existence of a co-integrating relationship between stock return volatility and explanatory variables suggests that there must be Granger causality in at least one direction. However, an ARDL model does not indicate the direction of temporal causality between the variables. Granger (1969) defines a time-series variable, $y_{t}$, to be causal for a variable $x_{t}$ if the former helps to improve the 1-step ahead forecasts for the latter. We investigate the causality at horizons beyond one period when the information set contains variables that are not directly involved in the Granger causality test. We apply arbitrarily three steps ahead to cover Granger cause-effects for the period of a quarter (as we use monthly data, three lags cover a quarter) by referring to the methods used in Rahman (2009). To account for the movements of the stock market volatilities, all explanatory variables are considered for the entire sample period.

\subsection{Data and Sample}

Monthly data from January 1995 to December 2018 (24 years) was collected from four emerging stock markets: Indonesia (JKSE), Malaysia (KLSE), the Philippines (PSE) and Thailand (SET), and one developed stock market: Singapore (STI), consisting of 17,280 observations. The starting data period is 1995 because all corporate variables for the five countries are available from 1995.

Notably, this period corresponds to the parallel growth in stock markets and economies in the ASEAN-5 countries including the 1997-98 Asian financial crisis and the 2008-09 global financial crisis. We are concerned by the problem of a structural break that is an unexpected shift in a (macroeconomic) time series. A structural break can lead to substantial forecasting errors and unreliability in the model (Damodar, 2007). The majority of econometric models applied in risk management assume the stability of the individual return (mean and volatility) process. However, data over a long period is more likely to cause structural breaks, as it covers a large number of structural disturbances. During the coverage of our sample (24 years), Southeast Asian countries experienced many transformations. To control structural breaks, we run breakpoint unit root tests and divide the period of study into three sub-periods accordingly. The results from unit root tests show that in most cases, there are three break periods corresponding well to economic events represented by the Asian financial crisis in 1997-1998 and the subprime mortgage crisis in 2008-2009 that originated in the US. We thus have three 
regimes: Regime I is from January 1995 to December 1997; Regime II is from January 1998 to June 2008, and Regime III is from July 2008 to December 2015.

\subsection{Variables}

The stock price index is a capitalisation-weighted index of all stocks listed on the main board of each stock exchange. We adopt these indices because they represent overall stock market performance. The construction and rationale of the use of each variable are discussed below.

\section{Return Volatility}

A monthly closing stock market index is used to calculate monthly return as follows:

The return in period $t, R_{t}=\log \left(P_{t}\right)-\log \left(P_{t-1}\right)$

the volatility of stock returns is estimated by the EGARCH model. We specify the mean equation with a constant, where $\log \left(P_{t}\right)-\log \left(P_{t-1}\right)$ is the monthly compounding return:

$$
\log \left(P_{t}\right)-\log \left(P_{t-1}\right)=c_{1}+\varepsilon_{t}
$$

For the variance specification, we employ an $\operatorname{EGARCH}(1,1)$ model:

$$
\log \left(\sigma_{t+1}^{2}\right)=\omega+\alpha\left|\frac{\varepsilon t}{\sigma t}\right|+\gamma \frac{\varepsilon t}{\sigma t}+\beta \log \left(\sigma_{t}^{2}\right)
$$

\section{Explanatory Variables}

Eleven explanatory variables are used to represent fundamental and behavioural factors, divided into four categories:

\section{(1) Macroeconomic variables}

The literature suggests that gross domestic product (GDP) and inflation rate be considered as goods market variables (e.g., Chen et al., 1986; Dhakal et al., 1993; Mukherjee and Naka, 1995; Wongbangpo and Sharma, 2002). Money supply and interest rate are considered to be money market variables. Stock price indices represent the performance of stock markets. In addition, an external competitiveness measure is included because Southeast Asian countries are tradeorientated. Hence, the measurement of external competitiveness plays a significant role in their economies. The exchange rate is considered to be an important factor in the foreign exchange market and trade balance and therefore can be used as a proxy for an external competitiveness 
measure (Bose, 2014). For trade-orientated developing economies, the exchange rate also plays a crucial role in stock market movements (Wongbangpo and Sharma, 2002). The nominal effective exchange rate of each country is included in the analysis.

Macroeconomic variables consist of gross domestic product (GDP), interest rates (INT), inflation rates (INF), money supply (MS), and exchange rates (EX). We use the seasonally adjusted growth of GDP in local currencies. Since monthly data on GDP is not available for all five countries, GDP quarterly series are interpolated to monthly frequency by using the expand procedure in the cubic spline. With respect to interest rates, we use monetary policy rates for Indonesia, the Philippines, Thailand, and Malaysia. This is because monetary authorities in these countries have shifted their policy emphasis from money aggregate towards the shortterm interest rate (policy rate) since the 1980s. Unlike other countries, however, monetary policy in Singapore has centred on the management of the exchange rate (Monetary Authority of Singapore, 2019). Accordingly, we employ the overnight rate (monthly data) for Singapore. Inflation rates are calculated as the percentage change in the Consumer Price Index. Narrow money (M1) is used to represent the money supply in all five countries. We use M1 rather than M2 or M3 because the most liquid portion of the money supply is measured by M1 (IMF, 1997). Exchange rates are represented by percentage changes in the effective exchange rates (EER).

(2) corporate variables

We employ a series of corporate variables comprising value-weighted return on equity (VWROE), the variance of earnings per share (VEPS), value-weighted price to book value (VWPTBV).

We estimate VWROE by the weighted mean of a non-empty set of data $\left\{R O E_{1}, R O E_{2}, \ldots\right.$, $\left.R O E_{n}\right\}$, as

$$
V W R O E=\frac{\sum_{i=1}^{N} W_{i} R O E_{i}}{\sum_{i=1}^{N} W_{i}}
$$

where $R O E_{i}=$ return on equity (\%) of company; $W_{i}=$ market capitalisation of the company; and $N=$ the sample size.

For each company with monthly sufficient data, we estimate VEPS as

$$
V E P S=\ln \left(\frac{1}{n} \sum_{i=1}^{N}\left(E P S_{i}-\mu\right)^{2}\right)
$$


where, $E P S_{i}=$ earnings per share of companies, and $N=$ the sample size.

We estimate VWPTBV by the weighted mean of a non-empty set of data $\left\{P T B V_{1}, P T B V_{2}, \ldots\right.$ , $\left.P T B V_{n}\right\}$, applying the method for $V W P T B V$ as

$$
\mathrm{VWPTBV}=\frac{\sum_{i=1}^{N} W_{i} P T B V_{i}}{\sum_{i=1}^{N} W_{i}}
$$

where $P T B V_{i}=$ price to book value of the company; $W_{i}=$ market capitalisation of the company; and $N=$ the sample size.

(3) Index composition (proxy of behavioural factors) consist of two variables: the percentage of the market capitalisation of firms less than 10 years old since establishment (PYOUNG) and aggregate turnover by volume (ATV). One possible explanation for changes in stock volatility over time is the age characteristics of firms. More specifically, the researchers proposed the age of firm is a good proxy for the uncertainty which may cause the market to behave differently from efficient markets (Pastor and Veronesi, 2003; Bennett and Sias, 2004; Wei and Zhang, 2006; Brown and Kapadia, 2007; Fink et al., 2010). This is because (1) the proportion of young firms (the firms are less than ten years old) is represented by the percentage of market capitalisation, and (2) trading volume is considered as a behavioural factor to test the herding behaviour proposed by Kumari and Mahakud (2015), Litimi et al. (2016), and BenSaïda (2017). We estimate PYOUNG by the weighted mean of a non-empty set of data $\left\{y_{1}, y_{2}, \ldots, y_{n}\right\}$, as

$$
\text { PYOUNG }=\frac{y}{M} * 100
$$

where $y$ is the market capitalisation of firms less than 10 years old since foundation and $M$ is the market capitalisation of all firms in the stock market.

We estimate aggregate turnover by volume of the stock market with

$$
A T V=\frac{\text { the total number of shares traded over a period }}{\text { the number of shares outstanding for the period }}
$$

All secondary data series, except political risk ratings $(P O L)$, are obtained from the DataStream database provided by Thomson Reuters. 
(4) The political risk includes political risk ratings $(P O L)$. Political risk used as one of the behavioural factors is because it relates to investors' confidence in investment and stock market performance (Tuyon and Ahmad, 2016). We follow Bartram et al. (2012) to use the political risk index of the International Country Risk Guide (ICRG). The political risk index is based on 100 points. Higher values represent more stable and higher quality government institutions. Thus, a higher value corresponds to a lower risk. We measure the quality of political and legal institutions using the ICRG Political Risk index because it measures a variety of institutional characteristics and the data is available for every month in respect of the five countries. Political risk ratings are obtained from the Political Risk Services Group (PRS Group), which is amongst the earliest commercial providers of political and country risk forecasts.

\section{Empirical Findings}

\subsection{Return volatility in the EGARCH process}

First of all, we use the student- $t$ EGARCH $(1,1)$ model to estimate monthly stock return volatility. Coefficient estimates are reported in Table 3.

\section{Insert Table 3 here.}

Table 3 shows that the asymmetry terms, $\gamma$, are negative for all the five countries and statistically significant in Malaysia and Singapore. This suggests that negative shocks imply a higher conditional variance of the next period than positive shocks. The significance of negative shock persistence or volatility asymmetry indicates that investors are more prone to react to negative news in comparison to positive news. These results suggest that the volatility spillover mechanism is asymmetric.

\subsection{Autoregressive Distributed Lag (ARDL) Model}

For the model selection, we undertake diagnostic checks to investigate whether the model can be accepted for rule formulation. The results for Regime II of Indonesia indicate that heteroskedasticity occurs in the model. We correct heteroskedasticity by using the HAC Consistent Covariance (Newey-West), which allows for adjusting the standard errors. 
Consequently, the original equation for Regime II of Indonesia is re-estimated. The results with adjusted standard errors are presented in Table 4.

Theoretically, the rationality of investors can be represented as significant impacts of fundamental factors (macroeconomic variables and corporate variables). Our results of Tables 4-8 show that stock market volatility is mainly driven by macroeconomic variables interest rates, exchange rates, inflation rates, GDP, and money supply, whereas corporate variables (return on equity, earnings per share, price to book value) have the least importance for all the five countries. These results are significant as they indicate that market participants do not behave irrationally, even though they do not perform with perfect rationality.

\section{Insert Tables 4-8 here.}

The results from Tables 4-8 demonstrate that interest rates are the critical macroeconomic factor influencing stock market volatility. Inflation targeting was adopted by Indonesia, the Philippines, and Thailand. ${ }^{3}$ However, monetary policy strategy in Malaysia is different from the policy in these three countries. In the process of interest rate targeting, monetary policy operates through short-term interest rates to attain the ultimate target, which is sustainable longrun economic growth, accompanied by price and financial stability (Bank Negara Malaysia, 2019). These circumstances explain the most influential role of policy rates, which are vital financial tools in the region. Besides policy rates, exchange rates affect stock market volatility significantly. Notably, the exchange rate plays a substantial role in Singapore. Unlike other countries in the same region, monetary policy in Singapore has centred on the management of the exchange rate (Monetary Authority of Singapore, 2019). Our results indicate that exchange rate stability, as the instrument of monetary policy, facilitates investors' perception of risk.

Our results also show that the signs of coefficients of interest rates differ between the periods. We have found both negative and positive coefficients. In the case of a negative relationship, a reduction in the interest rate encourages higher capital flows to the stock market from those expecting a higher rate of return (higher volatility). In the case of a positive relationship, a higher interest rate reduces the profitability of firms, and thus stock prices go down (stock market volatility increases). Although the effects of the interest rate have been found in both cases, positive relationships tend to be more significant. Our results show that the magnitudes

\footnotetext{
${ }^{3}$ Under an inflation targeting, the central banks implement their monetary policy through the selected key policy rates to achieve price stability and sustainable economic growth (See Nasir, 2019 for details).
} 
of positive signs are relatively large, while negative coefficients are comparatively small, for all five countries, which are in line with the results of Zare et al. (2013). These results indicate that the interest rate is generally considered as the cost of companies in Southeast Asian countries. The significant positive relationship between stock market volatility and the interest rate suggests that policymakers should constructively manage interest rates to aid the stability of the stock market.

Contrary to previous studies (Wang, 2007; Asai and Unite, 2008; Chuang et al., 2012; Shahzad et al., 2014), the trading volume does not play the most important role in affecting stock market volatility. Although trading volume is a behavioural factor that affects emerging market volatility more than developed market volatility, the proportion of young firms drives return volatility more significantly. The results show that proportion of young firm affects stock return volatility substantially in all three Regimes of the Philippines, whereas trading volume does not play a notable role. One possible explanation for this is that the impact of trading volume on return volatility analysed from many studies is generally measured on a daily basis. However, we use the monthly trading volume, which corresponds to the timeframe of the other variables in our analyses. This seems intuitively correct but the testing trading volume on a monthly basis has some drawbacks. As an illustration, the trading volume on a monthly frequency does not dramatically affect the performance. For low frequency, we are not able to perceive trading activities during each day that sometimes cause a halt in trading. Instead, in term of behavioural factors, return volatility mostly prevails in the trading of a large proportion of young firms (Jovanovic and Rousseau, 2001; Fink et al., 2010). More specifically, our results show that an increase in the percentage of young firms increases volatility. It is consistent with the findings of Jovanovic and Rousseau (2001) that changes in trading behaviour of younger listed firms drive idiosyncratic variance in stock returns. Likewise, Fink et al. (2010) also find that an increased proportion of young firms in the market leads to a significant fraction of the increase in firm-specific risk.

Tables 5-9 show high values of $R^{2}$ and adjusted $R^{2}$ in all the five countries, which indicates that the models have predictive value. The tests of disturbance term serial correlation $[\operatorname{LM}(1)$, $\operatorname{LM}(2), \operatorname{LM}(3)]$ are found to be statistically significant for Regime I in Malaysia and Singapore. However, Durbin-Watson statistics, which are the test of the first-order autocorrelation, indicate that there are no serial correlations. The ARCH tests suggest that the $p$-value of Regime II in Indonesia is lower than 0.01 ; thus, we reject the null hypothesis at the $1 \%$ level of 
significance. It indicates that heteroskedasticity occurs in the model. We correct for heteroskedasticity by using the HAC Consistent Covariance (Newey-West), which allows for adjusting the standard errors. The results of the re-estimated model are shown in Table 4.

Next, we employ a cumulative sum of recursive residuals (CUSUM) and cumulative sum of squared (CUSUMSQ) tests (Brown et al., 1975) to test the stability of the coefficients. The cumulative sums of recursive residuals are plotted, with the $5 \%$ critical lines. Figures 1-5 presents the plots of CUSUM and CUSUMSQ for the five countries. The tests generally indicate parameter stability in our estimated models.

\section{Insert Figures 1-5 here.}

\subsection{Bounds Test for Co-Integration}

The Bounds testing approach is used to test for the existence of a long-run relationship among the variables. This is achieved by conducting an F-test for the joint significance of the coefficients of variables concerning lagged levels. Co-integration implies that the variables move together and they do not diverge from the long-run equilibrium. In other words, any disequilibrium amongst the variables is a short-run phenomenon. Table 9 reports the results of the calculated F-statistics from the bounds test for co-integration analysis with unrestricted intercept and unrestricted trends for the five countries. The results for the five countries across the three Regimes show that the F-statistic is above the upper bound critical value and therefore the null hypothesis of no long-run relationship can be rejected. The results clearly indicate that there is a long-run relationship amongst the variables in all five countries and across all three Regimes. The existence of co-integrating relationships indicates that the nexus amongst the variables has been substantial over the sample period.

\section{Insert Table 9 here.}

\subsection{Pairwise Granger causality tests}

Table 10 presents the results of pairwise Granger causality tests, which indicate that the risk of return in Southeast Asia heavily relies on the macroeconomic factors considered, namely GDP, interest rate, inflation rate, money supply, and exchange rate. The significant effects of macroeconomic variables are consistent with the results of our ARDL analysis. Specifically, interest rate generates the most significant impact across the three Regimes compared to other 
explanatory variables. This is in line with the results from the ARDL model, where we demonstrate the high sensitivity of stock market volatility to the interest rate, as in Section 4.2.

Notably, the behavioural factors generate the second biggest impact on stock market volatility. Among them, aggregate turnover by volume is the most important behavioural factor, whereas political risk has the least impact. Moreover, stock return volatility causing explanatory variables is stronger than the reverse relationship. In Indonesia and Malaysia, stock market volatility affects aggregate turnover by volume significantly, but not vice versa. Interestingly, corporate variables make the least impact on return volatility compared to other groups of factors (i.e. macroeconomic factors and behavioural factors). In particular, it is evident that there is no causality between corporate variables and returns volatility in Malaysia. In summary, the insignificant impact of corporate variables from Granger causality tests is consistent with the findings from the ARDL model.

\section{Insert Table 10 here.}

\section{Robustness test}

Our diagnostic check over the EGARCH model confirms that the characteristics of stock return volatility in all stock market indices have been adequately captured. In other words, the chosen EGARCH framework is adequate for capturing all three elements of stock return volatility, namely the magnitude effect, the asymmetry or leverage effect, and the persistence in conditional volatility. We run other asymmetric GARCH models, PARCH and DCC-GARCH models, for robustness checks. Table 11 shows that the estimations by the EGARCH, PARCH and DCC-GARCH models generate similar results in terms of asymmetry and persistence of stock return volatility. More importantly, we find that the value of Akaike info criterion of three models is equal. Therefore, the EGARCH model is not inferior to other asymmetric models, and our results are robust to the EGARCH model and estimations.

\section{Insert Table 11 here.}

\section{Discussions}

5.1 Why do fundamental factors play crucial roles in influencing stock market volatility in Malaysia, Thailand, and Singapore, while behavioural factors affect stock market volatility more in Indonesia and the Philippines? 
Our investigations find significant differences in how fundamental and behaviour factors influence market volatilities of the developed and more-developed emerging (i.e. catch-up) markets as opposed to the developing markets. Our results reveal the following: (1) all the macroeconomic variables play more critical roles in Malaysia, Thailand, and Singapore than in Indonesia and the Philippines; (2) the corporate variables have significant impacts on Malaysia, Thailand, and Singapore, but insignificant effects in Indonesia and the Philippines; (3) the proportion of young firms has the least impact in stock market volatility in Malaysia, Thailand, and Singapore, but a substantial effect on all three Regimes in the Philippines; and (4) political risk has an enormous impact on all three Regimes in Indonesia. These are clear evidence to support our argument that behavioural factors affect stock market volatility more significantly than fundamental factors in the developing markets (Indonesia and the Philippines). In contrast, fundamental factors play a crucial role in stock market volatility in the developed (Singapore) and more developed emerging markets (Malaysia and Thailand). Our findings thus confirm the two testable hypotheses.

Our results support the theoretical reasoning discussed in Section 2 and are in line with some other studies on the impacts of investor sentiment (behavioural factors) on stock returns and volatilities in other stock markets. For example, in the US market, Baker and Wurgler (2006) find that investor sentiment is negatively related to stock returns. Corredor et al. (2015) compare the impact of investor sentiment on stock returns in the Central European markets and conclude that three less developed countries (i.e. the Czech Republic, Hungary and Poland) experience a stronger sentiment impact in pricing stocks compared to their developed counterparts in Europe. Kumari and Mahakud (2015) predict how investor sentiment affects asset volatility in the Indian market, and their results suggest that investor sentiment can create a systematic risk to stocks and, in turn, the risk influences the stock price. These studies share a common conclusion that behavioural factors play more critical roles in emerging markets, which is consistent with our contention that behavioural factors play a more significant role in emerging markets than developed and more developed emerging markets in ASEAN-5.

With respect to the corporate variables, we find that the price to book ratio is the primary corporate variable influencing stock market volatility. This may be attributed to the use of financial ratios in predicting stock returns that are theoretically rooted in asset pricing models such as the dividend discount model, earnings discount model, and residual income model (Bekaert et al., 2012; Bartram et al., 2012). These models argue that stock return is determined 
by fundamentals embedded in financial ratios and therefore such performance ratios as dividend-price ratios, earnings-price ratios, and price-to-book ratios support the fundamental analysis when assessing the future stock price. Our results support existing evidence that such financial ratios are robust in predicting returns and the growth of fundamentals (Lewellen, 2004; Lettau and Ludvigson, 2005; Hecht and Vuolteenaho, 2006; Cochrane, 2008; Lettau and Van Nieuwerburgh, 2008; Jiang and Lee, 2012). Our results provide further evidence to support the fundamental analysis that investors evaluate the changes in stock returns by considering a company's financial performance when making investment decisions.

Concerning our findings, why do our results show that Malaysia and Thailand are closer to Singapore as more developed markets rather than to Indonesia and the Philippines as emerging markets? Malaysia is one of the world's most dynamic stock markets, with a large banking sector that has proliferated since the 1960s (Pepinsky, 2011). Thailand's financial system has also experienced impressive growth since the 1960s (Pepinsky, 2011), even though it lags somewhat behind Malaysia. For instance, Malaysia and Thailand are the two well-known Asian "tiger cub" economies in the World Bank list, along with Singapore (French, 2017). In terms of the level of economic development and maturity of financial regulations and stock markets, Malaysia and Thailand are significantly ahead of Indonesia and the Philippines, although they are not officially recognised as developed countries like Singapore. Given the level of financial market development, investors in the three countries tend to be more rational and make investment decisions mainly based on fundamentals, like those in Singapore.

Nevertheless, Indonesia and the Philippines remain relatively underdeveloped compared to their counterparts in ASEAN-5. An important finding is that political risk has substantial impacts on all the three Regimes in Indonesia, which suggests that Indonesia has more political risk compared to the other four countries (as measured by average political risk index). Expectedly, an increase in political risk increases stock market volatility. Bartram et al. (2012) point out that countries with more political risk are expected to have riskier stock returns. Most remarkably, we have not found a significant impact of political uncertainty in affecting stock market volatility in the other three markets, i.e. Malaysia, Thailand, and Singapore, and especially there is no political risk in all three Regimes for Singapore. This is not surprising, as Singapore has the lowest political risk among the ASEAN-5 because it has the highest UN Political Stability Index of them all. However, Indonesia shows the highest fluctuations in interest rate, inflation rate, money supply and exchange rate. Our results provide further 
evidence to support the assertion that Indonesia's and Philippines' economies and political conditions remain unstable.

\subsection{Will our results prove, to some extent, the process of ASEAN-5's integration?}

Our findings provide insights that ASEAN-5 has made encouraging progress in the integration of the region, as we observe that there is a long-run relationship among all five countries, with Malaysia and Thailand being closer to Singapore in terms of economic development, corporate values, and political stability. However, this integration is not complete because the relationship is not always stable, as our results relating to sub-periods in the two emerging markets, i.e. Indonesia and the Philippines, show. This suggests that segmentation still exists in ASEAN-5 because Indonesia and the Philippines remain relatively underdeveloped.

An integrated regional stock market is essential for both investors and government policymakers. If a regional stock market is integrated with liquidity, capital can easily flow between all member countries to allocate funds productively and efficiently and reduce the cost of investment (Click and Plummer, 2005; Kumar, 2015). Moreover, the integration of regional stock market will provide investors with better opportunities to pursue diversified portfolio investments and risk reduction (Narayan et al., 2004). For policymakers, an intra-regional integrated market will not only help broaden financial products and attract international investors to this region but, most importantly, will also strengthen regional economic infrastructure and improve the impacts of financial regulations and monetary policies towards the region's financial stability and competitive position in the global market (Chien et al., 2015).

ASEAN is the fourth largest trading region globally and an investment icon in the world's financial markets. Since its establishment in 1967, in order to strengthen the prosperity of all member countries and enhance the competitiveness of the region in the world, ASEAN has been working and co-operating to accelerate the progress and integration of economic growth, social progress and cultural development in the region as a whole -the so-called: One Version, One Identity Maxim- towards "a fully liberalised, single-region common market with a free flow of goods, services, labour, and capital” (Lee and Jeong, 2016, p. 2069).

Measuring/Assessing/Evaluating a regional stock market's integration can be varied. In the case of ASEAN-5, for instance, using the time series technique of cointegration, Click and Plummer (2005) find that ASEAN-5 stock markets are integrated economically, but the 
integration process is far from complete. Goh et al. (2005) look at the intertemporal linkages of the ASEAN-5 stock markets in response to the Asian financial crisis using stock indices, and their findings suggest that ASEAN-5 underwent a structural change after mid-1997, caused by the Asian financial crisis when Indonesia led the movements. In a similar line, Lim (2009) suggests the level of the integration and interdependence of the ASEAN-5 markets increased after the 1997 Asian financial crisis; and Truchis and Keddad (2013) add to evidence that the ASEAN-5 turn to more integrated after the 1997 Asian financial crisis because of equilibrium errors responding more rapidly to the shocks. Truchis and Keddad (2016) examine perceived commonality in volatility movements to assess the performance of financial and regulatory activities and suggest that a global integration process drives the most developed markets of the region while emerging markets are less affected. Our study evaluates the integration of the ASEAN-5 markets from a fresh perspective - how stock return volatility would be influenced by both fundamental and behavioural factors in the regional market, albeit it does not directly measure the degree of the ASEAN-5 markets' integration through convergence or comovement, which is beyond the purpose of our study. We find similar results with that in these studies to prove that ASEAN-5 is integrated into some ways and the integration process is encouraging, but not finished.

\subsection{Why can our finding evaluate regional fiscal and monetary policies?}

Our findings reveal that interest rates, exchange rates, and inflation rates are the key macroeconomic factors driving stock market volatility in the ASEAN-5, whereas GDP has a less impact. As GDP is affected by fiscal policies via aggregate demand (AD), the results suggest that monetary policies play a more critical role in the region than fiscal policies. The main characteristic of monetary policy frameworks in Southeast Asian countries is inflation targeting, which is adopted in most states (Indonesia, the Philippines, and Thailand in our sample). For inflation targeting, the central banks implement their monetary policies through the selected key policy rates to achieve price stability and sustainable economic growth. These circumstances substantiate the most influential role of policy rates in stock market volatility via vital financial tools and inflation rates.

Governments' policies are essential vehicles for stimulating regional integration; however, the effects are, to a large extent, dependent on receivers' (countries) economic situation, where only an extended period can capture its full economic cycle (i.e., economic boom, recession and recovery). Some policy impacts can be measured utilising macroeconomic fundamentals 
such as GDP, money supply, interest rate, inflation rate and exchange rate (Wongbangpo and Sharma, 2002). As this study has advantages of incorporating a sufficiently long-time coverage (1995-2018), which includes two financial crises, i.e., Asian and global financial crises, we argue that our findings relating to the impacts of fiscal and monetary policies provide historic evidence of market movements in this region. Specifically, our data comprise macroeconomic variables (GDP, the money supply, the interest rate, the inflation rate and the exchange rate) and show that Indonesia and the Philippines, on average, have high inflation rates over 24 years compared to the other three countries in the region. Moreover, Indonesia shows the highest fluctuations in interest rates, inflation rates, money supply, and exchange rates. According to IMF (2016), economic stability refers to an absence of excessive fluctuations in the macroeconomic indicators as well as low and stable inflation. Therefore, the statistics substantiate our findings that Indonesia and the Philippines remain economically unstable; while these macroeconomic variables are stable in Malaysia, Thailand and Singapore.

\subsection{What are the meanings of the three Regime results?}

We, based on the structural breaks in the Unit Root Tests, divide our 24-year data into three sub-periods for Regime I (from January 1995 to December 1997), Regime II (from January 1998 to June 2008) and Regime III (from July 2008 to December 2018) representing the periods of before the Asian Financial Crisis, between the Asian Financial Crisis and the Global Financial Crisis, and after the Global Financial Crisis, respectively. This separation is to capture the differences between the three Regimes represented by the two financial crises. The results from the three Regimes provide strong evidence in support of our main findings above. Specifically, we find: (1) there is a long-run relationship from Bounds Test for co-integration analysis for all the variables in all five countries across all three Regimes. This result confirms the integration level of this regional market. (2) fundamental factors are stable and associated with Malaysia, Thailand and Singapore across all the Regimes. Our results consistently show that behavioural factors are more concerned with Indonesia and the Philippines across the three Regimes. For instance, market volatility of the Philippines is shaped by young firms' behaviour in all the three Regimes, while corporate variables have an insignificant impact in Regime III of Indonesia. These provide further evidence that Malaysia and Thailand are moving closer to Singapore being more-developed emerging countries in the region; while Indonesia and the Philippines remained underdeveloped in respect of economic development, corporate values, and political stability. 


\section{Conclusions}

For the first time, and by reference to an economically significant period in ASEAN-5 countries, we incorporate fundamental and behavioural factors into our study and examine their roles in stock market volatility in this region. Through extended period coverage and rigorous analyses, our study adds a new perspective and provides fresh evidence to the academic debate and enriches our understanding of the role of fundamental and behaviour factors in market movements. We find instructive results for the relative force that the selected variables impose on stock market volatility.

Three key findings emerge: first, our study confirms that fundamental factors are important in stock market volatility in the developed (Singapore) and more developed emerging markets (Malaysia and Thailand) than in Indonesia and the Philippines; conversely, behaviour factors play a more crucial role in the developing markets such as Indonesia and the Philippines than Malaysia, Thailand, and Singapore. Second, we provide fresh evidence that the region's integration among the ASEAN-5 has made good progress. Third, we find that the monetary policies are more effective than fiscal policies in the region. In addition, the results from the three Regimes analysis provide an endorsement to our main findings.

Our findings provide several policy implications: (1) As economic and stock market integration is one of the most critical long-term regional policies, effective policies should be carefully designed and implemented to assist with Indonesia and the Philippines to catch-up with their neighbours. (2) As trading volatility can result in improper trading and other irregular activities, and the impact of behavioural factors on decision-making can cause market instability, financial regulators need to pay close attention to Indonesia's and the Philippines' markets, to maintain an orderly market and enhance market transparency and integrity and hence stabilise ASEAN-5 economies and financial markets as a whole. (3) Our results suggest that Indonesia experiences the highest fluctuations in interest rates, inflation rates, money supply and exchange rates and has the most unstable political risk. This suggests that special measures for Indonesia are needed to prevent financial crisis contagion in this region. (4) Our findings indicate that there is still segmentation and imbalance between member countries in the region. A practical approach might be for central banks in these countries to work closely and cooperatively in setting up monetary policies to speed up integration and achieve stabilised regional economic development, enabling these countries to compete in the global market. 
We finally submit that our study raises issues for future research. It suggests that new investigations could divide regimes based on other factors, segmenting them according to whether they have undergone financial crises or not, and examining how fundamental and behavioural factors have different impacts upon them. Research can also consider whether differences are related to the development level of a country by incorporating variables that measure this value. Studies may also examine political and geographical crises, as well as regulatory regime changes. Nonetheless, further extensions can be applied to all countries in the region, or to other regional markets, including both developed and developing countries, such as European, Asian, African and North American markets, to expand and support the generalisations drawn from our study. 


\section{References}

Ali, N., Nassir, A.M., Hassan, T., Abidin, S. 2010. Short run stock overreaction: Evidence from Bursa Malaysia. International Journal of Economics and Management 4(2), 319-333.

Asai, M., Unite, A., 2008. The relationship between stock return volatility and trading volume: the case of the Philippines. Applied Financial Economics, 18, 1333-1341.

Bakar, S., Yi, A. N. C. 2016. The impact of psychological factors on investors' decision making in Malaysian stock market: A case of Klang Valley and Pahang. Procedia Economics and Finance 35, $319-328$.

Baker, H.K., Hargrove, M.B., Haslem, J.A. 1977. An empirical analysis of the risk return preferences of individual investor. Journal of Financial and Quantitative Analysis 12, 377-389.

Baker, M., Wurgler, J. 2006. Investor sentiment and the cross-section of stock returns. Journal of Finance 61, 1645-1680.

Baker, M., Wurgler, J. 2007. Investor sentiment in the stock market. Journal of Economic Perspectives 21, 129-151.

Bank Negara Malaysia, 2019. Monetary Policy. available at http://www.bnm.gov.my/index.php?ch=en press\&pg=en press\&ac=3071\&lang=en.

Bartram, S.M., Brown, G. and Stulz, R.M., 2012. Why Are U.S. Stocks More Volatile? The Journal of Finance, 67 (4), 1329-1370.

Bekaert, G., Robert, J., Hodrick and Zhang, X., 2012. Aggregate idiosyncratic volatility. Journal of Financial and Quantitative Analysis 47, 1155-1185.

Bennett, J. and Sias, R., 2004. Why has firm-specific risk increased over time? Unpublished working paper. Pullman: Washington State University.

BenSaïda, A., 2017. Herding effect on idiosyncratic volatility in U.S. industries. Finance Research Letters, 23, 121-132.

Black, F., 1986. Noise. Journal of Finance, 41, 529-543.

Bose, D. 2014. Real exchange rates and international competitiveness - Concepts, measures and trends in New Zealand. Working paper, available from: https://www.nzae.org.nz/wpcontent/uploads/2015/01/Dhritidyuti - Real Exchange Rate and CompetitivenessSMALL.pdf.

Brown, G., Kapadia, N., 2007. Firm-specific risk and equity market development. Journal of Financial Economics, 84, 358-388.

Brown, R. L., Durbin, J., Evans, J.M. 1975. Techniques for testing the constancy of regression relationships over time (with discussion). Journal of the Royal Statistical Society B, 37, 149192.

Click, R.W., Plummer, M.G., 2005. Stock market integration in ASEAN after the Asian financial crisis. Journal of Asian Economics 16, 5-28. 
Chang, E.C., Dong, S., 2006. Idiosyncratic volatility, fundamentals, and institutional herding: Evidence from the Japanese stock market. Pacific-Basin Finance Journal 14, 135-154.

Chen, N.F., Roll, R., Ross, S.A., 1986. Economic forces and the stock market. Journal of Business 59, 383-403.

Chien, M.S., Lee, C. C., Hu, T.C., Hu, H. T. 2015. Dynamic Asian stock market convergence: Evidence from dynamic cointegration analysis among China and ASEAN-5. Economic Modelling 51, 84-98.

Chuang, W.I., Liu, H.H., Susmel, R. 2012. The bivariate GARCH approach to investigating the relation between stock returns, trading volume, and return volatility. Global Finance Journal, 23, 1-15.

Cochrane, J.H. 2008. The dog that did not bark: A defense of return predictability. The Review of Financial Studies 21(4), 1533-1575.

Corredor, P., Ferrer, E., Santamaria, R. 2015. The impact of investor sentiment on stock returns in emerging markets: The case of Central European markets. Journal Eastern European Economics 53(4), 328-355.

De Long, B. J., Shleifer, A., Summers, L.H., Waldmann, R. 1990. Noise trader risk in financial markets, Journal of Political Economy 98, 703-738.

Dhakal, D., Kandil, M. and Sharma, S.C., 1993. Causality between the money supply and share prices: a VAR investigation. Quarterly Journal of Business and Economics, 32 (3), 52-74.

Damodar, G. 2007. Basic Econometrics. New Delhi: Tata McGraw-Hill. Dickey, D. A., Fuller, W. A. 1979. Distribution of the estimators for Autoregressive Time Series with a Unit Root. Journal of the American Statistical Association 74, 427-431.

Engle, R.F., 1982. Autoregressive conditional heteroskedasticity with estimates of the variance of U.K. inflation. Econometrica 50, 987-1008.

Engle, R.F., Granger, C.W.J. 1987. Co-Integration and Error Correction: Representation, Estimation, and Testing. Econometrica 55, 251-276.

Fama, E.F., French, K.R., 1992. The cross-section of expected returns. Journal of Finance 47, 427-465.

Fama, E.F. and French, K.R., 2004. New lists: Fundamentals and survival rates. Journal of Financial Economics, 73, 229-269.

Fama, E.F., French, K. R. 2015. A five-factor asset pricing model. Journal of Financial Economics 116, 1-22.

Fink, J.K., Fink, E., Grullon, G., Weston, J.P., 2010. What drove the increase in Idiosyncratic Volatility during the internet boom? Journal of Financial and Quantitative Analysis 45, 12531278 .

Fisher, K. L., Statman, M. 2000. Investor sentiment and stock returns. Financial Analysts Journal 56, 16-23. 
Fisher, K.L., Statman, M. 2004. Sentiment, value, and market timing. Journal of Investing 13, $10-21$.

French, J. 2017. Asset pricing with investor sentiment: On the use of investor group behavior to forecast ASEAN markets. Research in International Business and Finance 42, 124-148.

Friedman, M. 1953. The case of flexible exchange rates essays in positive economics, Chicago: University of Chicago Press.

Francis, J., Soffer, L. 1997. The relative informativeness of analysts' stock recommendations and earnings forecast revisions. Journal of Accounting Research 35, 193-211.

Gaspar, J.M., Massa, M. 2006. Idiosyncratic volatility and product market competition. Journal of Business 79, 3125-3152.

Goh, K.L., Wong, Y.C., Kok, K.L. 2005. Financial crisis and intertemporal linkages across the ASEAN-5 stock markets. Review of Quantitative Finance and Accounting 24, 359-377.

Gospodinov, N., Jamali, I. 2012. The effects of federal funds rate surprises on S\&P 500 volatility and volatility risk premium. Journal of Empirical Finance 19, 497-510.

Granger, C.W.J. 1969. Investigating causal relations by econometric models and cross-spectral methods. Econometrica 37, 424-459.

Gregoriou, G. N. 2009. Stock Market Volatility. New York: CRC Press.

Guo, H., Savickas, R., 2008. Average idiosyncratic volatility in G7 countries. Review of Financial Studies 21, 1259-1296.

Gupta, R., Guidi, F. 2012. Cointegration relationship and time varying co-movements among Indian and Asian developed stock markets. International Review of Financial Analysis 21,1022.

Hecht, P., Vuolteenaho, T. 2006. Explaining returns with cash-flow proxies. The Review of Financial Studies 19(1), 159-194.

IMF 1997. International Monetary Fund: Manual on Monetary and Financial Statistics.

IMF 2018. IMF: World Economic Outlook (WEO) Database, April 2018.

IMF 2016. Macroeconomic Policy and Poverty Reduction. Available at https://www.imf.org/external/pubs/ft/exrp/macropol/eng/

Jiang, X., Lee, B.S. 2012. Do decomposed financial ratios predict stock returns and fundamentals better? The Financial Review 47, 531-564.

Jiranyakul, K. 2011. On the risk-return tradeoff in the stock exchange of Thailand: New evidence. Asian Social Science 7, 115-123.

Johansen, S. 1991. Estimation and hypothesis testing of cointegration vectors in Gaussian vector autoregressive models. Econometrica 59, 1551-1580. 
Johansen, S. 1995. Likelihood-Based Inference in Cointegrated Vector Autoregressive Models. Oxford, Oxford University Press.

Jovanovic, B., Rousseau, P. 2001. Why wait? A century of life before IPO. American Economic Association Papers and Proceedings 91, 336-341.

Konrad, E. 2009. The impact of monetary policy surprises on asset return volatility: the case of Germany. Financial Markets and Portfolio Management 23, 111-135.

Kumar, S. 2015. Regional integration, capital mobility and financial intermediation revisited: Application of general to specific method in panel data. Journal of International Financial Markets, Institutions \& Money 36, 1-17.

Kumari, J., Mahakud, J. 2015. Does investor sentiment predict the asset volatility? Evidence from emerging stock market India. Journal of Behavioral and Experimental Finance 8, 25-39.

Lee, K.L. 2009. Convergence and interdependence between ASEAN-5 stock markets. Mathematics and Computers in Simulation. 79, 2957-2966.

Lee, G., Jeong, J. 2016. An investigation of global and regional integration of ASEAN economic community stock market: Dynamic risk decomposition approach. Emerging Markets Finance and Trade 52, 2069-2086.

Lettau, M., Ludvigson, S. 2005. Expected returns and expected dividend growth. Journal of Financial Economics 76(3), 583-626.

Lettau, M., Nieuwerburgh, S.V. 2008. Reconciling the return predictability evidence. The Review of Financial Studies 21(4), 1607-1652.

Lewellen, J. 2004. Predicting returns with financial ratios. Journal of Financial Economics 74 (2), 209-235.

Liew, V.K.S. 2004. Which lag length selection criteria should we employ? Economics Bulletin $3,1-9$.

Lim, L.K. 2009. Convergence and interdependence between ASEAN-5 stock markets. Mathematics and Computers in Simulation 79, 2957-2966.

Lim, K. P., Hinich, M. J. 2005. Non-linear market behavior: eventsdetection in the Malaysian stock market. Economics Bulletin 7(6), 1-5.

Litimi, H., BenSaïda, A. and Bouraoui, O., 2016. Herding and excessive risk in the American stock market: A sectoral analysis. Research in International Business and Finance, 38, 6-21.

Lu, S., Zhao, J., Wang, H., Ren, R. 2018. Herding boosts too-connected-to-fail risk in stock market of China. Physica A 505, 945-964.

Lütkepohl, H. 1993. Introduction to Multiple Time Series Analysis, 2nd Ed., Springer-Verlag, Berlin.

Maysami, R. C., Koh, T. S. 2000. A vector error correction model of the Singapore stock market. International Review of Economics and Finance 9, 79-96. 
Mittnik, S., Robinzonov, N., Spindler, M. 2015. Stock market volatility: Identifying major drivers and the nature of their impact. Journal of Banking \& Finance 58, 1-14.

Monetary Authority of Singapore, 2019. Monetary Policy Framework. available at https://www.mas.gov.sg/monetary-policy/Singapores-Monetary-Policy-Framework.

Mukherjee, T.K. and Naka, A., 1995. Dynamic relations between macroeconomic variables and the Japanese stock market: an application of a vector error correction model. Journal of Financial Research, 18 (2), 223-237.

Narayan, P., Smyth, R., Nandha, M. 2004. Interdependence and dynamic linkages between the emerging stock markets of South Asia. Accounting and Finance 44, 419-439.

Narayan, P. K. 2005. The saving and investment nexus for China: evidence from cointegration tests. Applied Economics 37(17), 1979-1990.

Narayan, S., Narayan, P. K. 2005. An empirical analysis of Fiji's import demand function", Journal of Economic Studies 32 (2),158-168.

Nasir, M. A. 2019. A quarter century of inflation targeting and exchange rate pass-through: Evidence from the first three movers, available https://www.researchgate.net/publication/323765788.

Nelson, D. 1991. Conditional Heteroskedasticity in Asset Returns: A New Approach. Econometrica 59, 347-370.

Pastor, L. and Veronesi, P., 2003. Stock valuation and learning about profitability. Journal of Finance, 58, 1749-1789.

Pepinsky, T.B., 2011. The Political Economy of Financial Development in Southeast Asia, New York, Oxford University Press.

Pesaran, M.H., Shin, Y. 1999. An Autoregressive Distributed Lag Modelling approach to cointegration analysis. In: S. Strom ed. Econometrics and Economic Theory in the 20th Century: The Ragnar Frisch Centennial Symposium, Cambridge: Cambridge University Press.

Pesaran, M.H., Shin, Y., Smith, R. 2001. Bound testing approaches to the analysis of level relationships. Journal of Applied Econometrics 16, 289-326.

Poon, S., Taylor, S.J. 1991. Macroeconomic factors and the UK stock market. Journal of Business and Accounting 18, 619-636.

Rahman, M.A., 2009. Industry-level stock returns volatility and aggregate economic activity in Australia. Applied Financial Economics, 19, 509-525.

Safdar, I., 2000. Why has idiosyncratic volatility increased? Unpublished working paper. New York: University of Rochester.

Schmeling, M. 2009. Investor sentiment and stock returns: Some international evidence. Journal of Empirical Finance 16, 394-408. 
Selden, G.C., 1912. Psychology of the stock market: Human impulses lead to speculative disasters. New York: Ticker Publishing.

Shahzad, H., Duong, H.N., Kalev, P.S., Singh, H. 2014. Trading volume, realized volatility and jumps in the Australian stock market. Journal of International Financial Markets, Institutions \& Money 31, 414-430.

Sharma, S. C., Wongbangpo, P. 2002. Long-term trends and cycles in ASEAN stock markets. Review of Financial Economics 11(4), 299-315.

Shefrin, H., Statman, M. 1994. Behavioral capital asset pricing theory. Journal of Financial and Quantitative Analysis 29, 323-349.

Shleifer, A., Summers, L. H. 1990. The noise trader approach to finance, Journal of Economic Perspectives 4, 19-33.

Statman, M. 2014. Behavioral finance: Finance with normal people. Borsa Istanbul Review 14, $65-73$.

Subrahmanyam, A., 2007. Behavioural finance: a review and synthesis. European Financial Management 14,12-29.

Truchis, G.D., Keddad, B, 2013. Southeast Asian monetary integration: New evidences from fractional cointegration of real exchange rates, Journal of International Financial Markets, Institutions \& Money 26, 394-412.

Truchis, G.D., Keddad, B, 2016. Long-run comovements in East Asian stock market volatility. Open Economies Review 27, 969-986.

Tuyon, J., Ahmad, Z. 2016. Behavioural finance perspectives on Malaysian stock market efficiency. Borsa Istanbul Review 16(1), 43-61.

Wang, J., 2007. Foreign equity trading and emerging market volatility: Evidence from Indonesia and Thailand. Journal of Development Economics, 84, 798-811.

Wei, S.X., Zhang, C., 2006. Why did individual stocks become more volatile? Journal of Business, 79, 259-292.

Wooldridge, J.M. 2015. Introductory Econometrics: A Modern Approach, Edition 6, Boston, Cengage Learning.

Wongbangpo, P., Sharma, S. C. 2002. Stock market and macroeconomic fundamental dynamic interactions: ASEAN-5 countries. Journal of Asian Economics, 13, 27-51.

Zare, R., Azali, M., Habibullah, M.S.,2013. Monetary policy and stock market volatility in the ASEAN5: Asymmetries over bull and bear markets. Procedia Economics and Finance 7, 1827. 
Table 1: Correlogram of the standardised residuals: Q-statistics

\begin{tabular}{|c|c|c|c|c|}
\hline Country & $\mathbf{A C}$ & PAC & Q-Stat & Prob* \\
\hline \multirow[t]{10}{*}{ Indonesia } & 0.1290 & 0.1290 & 4.8179 & 0.0280 \\
\hline & -0.0220 & -0.0400 & 4.9624 & 0.0840 \\
\hline & 0.0410 & 0.0500 & 5.4525 & 0.1420 \\
\hline & 0.0090 & -0.0040 & 5.4765 & 0.2420 \\
\hline & -0.0260 & -0.0240 & 5.6785 & 0.3390 \\
\hline & -0.0360 & -0.0310 & 6.0518 & 0.4170 \\
\hline & -0.0160 & -0.0090 & 6.1246 & 0.5250 \\
\hline & 0.0390 & 0.0430 & 6.5846 & 0.5820 \\
\hline & -0.0580 & -0.0690 & 7.5985 & 0.5750 \\
\hline & -0.0010 & 0.0200 & 7.5990 & 0.6680 \\
\hline \multirow[t]{10}{*}{ Malaysia } & -0.0640 & -0.0640 & 1.1877 & 0.2760 \\
\hline & 0.0700 & 0.0670 & 2.6305 & 0.2680 \\
\hline & -0.0240 & -0.0160 & 2.7987 & 0.4240 \\
\hline & 0.0630 & 0.0570 & 3.9704 & 0.4100 \\
\hline & 0.0550 & 0.0660 & 4.8702 & 0.4320 \\
\hline & 0.0490 & 0.0490 & 5.5858 & 0.4710 \\
\hline & 0.0250 & 0.0260 & 5.7722 & 0.5670 \\
\hline & -0.0440 & -0.0490 & 6.3484 & 0.6080 \\
\hline & 0.0840 & 0.0710 & 8.4735 & 0.4870 \\
\hline & -0.0220 & -0.0150 & 8.6125 & 0.5690 \\
\hline \multirow[t]{10}{*}{ Philippines } & 0.0520 & 0.0520 & 0.7893 & 0.3740 \\
\hline & -0.0110 & -0.0140 & 0.8266 & 0.6610 \\
\hline & 0.0760 & 0.0780 & 2.5267 & 0.4700 \\
\hline & -0.0290 & -0.0370 & 2.7668 & 0.5980 \\
\hline & -0.0540 & -0.0480 & 3.6169 & 0.6060 \\
\hline & 0.0270 & 0.0260 & 3.8356 & 0.6990 \\
\hline & -0.0150 & -0.0150 & 3.9025 & 0.7910 \\
\hline & -0.0720 & -0.0640 & 5.4430 & 0.7090 \\
\hline & 0.0750 & 0.0770 & 7.1420 & 0.6220 \\
\hline & -0.0310 & -0.0410 & 7.4308 & 0.6840 \\
\hline \multirow[t]{10}{*}{ Thailand } & 0.0660 & 0.0660 & 1.2668 & 0.2600 \\
\hline & 0.0170 & 0.0120 & 1.3465 & 0.5100 \\
\hline & 0.1240 & 0.1220 & 5.8200 & 0.1210 \\
\hline & 0.0480 & 0.0330 & 6.5038 & 0.1650 \\
\hline & -0.0020 & -0.0100 & 6.5048 & 0.2600 \\
\hline & -0.0360 & -0.0520 & 6.8803 & 0.3320 \\
\hline & 0.0910 & 0.0890 & 9.3395 & 0.2290 \\
\hline & 0.0040 & -0.0070 & 9.3435 & 0.3140 \\
\hline & -0.0610 & -0.0530 & 10.4570 & 0.3150 \\
\hline & -0.0440 & -0.0580 & 11.0440 & 0.3540 \\
\hline \multirow[t]{5}{*}{ Singapore } & 0.0300 & 0.0300 & 0.2630 & 0.6080 \\
\hline & 0.0860 & 0.0850 & 2.4015 & 0.3010 \\
\hline & 0.0240 & 0.0190 & 2.5667 & 0.4630 \\
\hline & -0.0070 & -0.0150 & 2.5808 & 0.6300 \\
\hline & 0.0260 & 0.0230 & 2.7730 & 0.7350 \\
\hline
\end{tabular}




\begin{tabular}{llll}
0.0140 & 0.0140 & 2.8271 & 0.8300 \\
0.0510 & 0.0470 & 3.5969 & 0.8250 \\
0.0250 & 0.0190 & 3.7777 & 0.8770 \\
0.0480 & 0.0390 & 4.4629 & 0.8780 \\
-0.0520 & -0.0610 & 5.2739 & 0.8720 \\
\hline
\end{tabular}

Table 2: Heteroskedasticity test: ARCH

\begin{tabular}{|c|c|c|}
\hline Country & Obs*R-squared & Prob. Chi-Square(1) \\
\hline Indonesia & 0.0001 & 0.9935 \\
\hline Malaysia & 1.1745 & 0.2785 \\
\hline Philippines & 0.2444 & 0.6210 \\
\hline Thailand & 0.0488 & 0.8251 \\
\hline Singapore & 0.2051 & 0.6506 \\
\hline
\end{tabular}


Table 3: Statistics of return volatility in the EGARCH process

\begin{tabular}{|c|c|c|c|}
\hline Country & & Coefficient & Prob. \\
\hline \multirow{4}{*}{ Indonesia } & $\omega$ & -0.1162 & 0.0340 \\
\hline & $\alpha$ & 0.2202 & 0.0028 \\
\hline & $\gamma$ & -0.0160 & 0.7421 \\
\hline & $\beta$ & 0.9870 & 0.0000 \\
\hline \multirow[t]{4}{*}{ Malaysia } & $\omega$ & -0.1451 & 0.0287 \\
\hline & $\alpha$ & 0.2826 & 0.0008 \\
\hline & $\gamma$ & -0.1037 & 0.0100 \\
\hline & $\beta$ & 0.9750 & 0.0000 \\
\hline \multirow[t]{4}{*}{ Philippines } & $\omega$ & -0.0265 & 0.8067 \\
\hline & $\alpha$ & 0.2034 & 0.0227 \\
\hline & $\gamma$ & -0.0475 & 0.2885 \\
\hline & $\beta$ & 0.9635 & 0.0000 \\
\hline \multirow{4}{*}{ Thailand } & $\omega$ & -0.1210 & 0.1083 \\
\hline & $\alpha$ & 0.2378 & 0.0057 \\
\hline & $\gamma$ & -0.0557 & 0.1634 \\
\hline & $\beta$ & 0.9822 & 0.0000 \\
\hline \multirow[t]{4}{*}{ Singapore } & $\omega$ & -0.0446 & 0.6282 \\
\hline & $\alpha$ & 0.3101 & 0.0040 \\
\hline & $\gamma$ & -0.1307 & 0.0229 \\
\hline & $\beta$ & 0.9440 & 0.0000 \\
\hline
\end{tabular}


Table 4: ARDL (Indonesia)

\begin{tabular}{|c|c|c|c|c|c|}
\hline \multicolumn{2}{|c|}{ Regime I: 1995:01-1997:12 } & \multicolumn{2}{|c|}{ Regime II: 1998:01-2008:06 } & \multicolumn{2}{|c|}{ Regime III: 2008:07-2018:12 } \\
\hline $\operatorname{MRV}(-1)$ & $-0.8037(-1.7949)$ & $\operatorname{MRV}(-1)$ & $0.3824(2.8490)^{* *}$ & $\operatorname{MRV}(-1)$ & $0.7494(10.8657)^{* *}$ \\
\hline GDP & $-0.1490(-3.3308)^{* *}$ & $\operatorname{MRV}(-2)$ & $0.2069(1.8925)$ & $\operatorname{MRV}(-2)$ & $-0.0008(-0.0092)$ \\
\hline $\operatorname{GDP}(-1)$ & $0.1584(4.4310)^{* *}$ & $\operatorname{MRV}(-3)$ & $0.1444(1.4420$ & $\operatorname{MRV}(-3)$ & $0.1343(1.8398)$ \\
\hline INT & $0.0841(3.3827)^{* *}$ & GDP & $-0.1171(-2.1835)^{*}$ & GDP & $0.0073(0.3443)$ \\
\hline $\operatorname{INT}(-1)$ & $0.1145(2.3436)^{*}$ & GDP(-1) & $0.2427(2.7402)^{* *}$ & INT & $0.0741(1.7975)$ \\
\hline INF & $-0.0751(-1.9311)$ & GDP(-2) & $-0.1453(-3.0583)^{* *}$ & INT(-1) & $-0.0505(-1.3010)$ \\
\hline $\operatorname{INF}(-1)$ & $0.0704(2.2955)^{*}$ & INT & $-0.0278(-3.9753)^{* *}$ & INF & $0.0099(1.5175)$ \\
\hline MS & $0.0291(3.1491)^{*}$ & INT(-1) & $0.0092(0.7048)$ & MS & $-0.0017(-0.5986)$ \\
\hline $\operatorname{MS}(-1)$ & $-0.0071(-1.0134)$ & $\operatorname{INT}(-2)$ & $0.0188(1.8750)$ & $\mathrm{MS}(-1)$ & $-0.0032(-1.0667)$ \\
\hline $\mathrm{EX}$ & $-0.0042(-0.6451)$ & INF & $0.0142(2.7053)^{* *}$ & $\operatorname{MS}(-2)$ & $0.0059(2.0931)^{*}$ \\
\hline $\mathrm{EX}(-1)$ & $0.0244(2.4032)^{*}$ & $\operatorname{INF}(-1)$ & $-0.0023(-0.4206)$ & $\mathrm{EX}$ & $-0.0008(-0.6321)$ \\
\hline VWROE & $0.0123(2.0526)$ & $\operatorname{INF}(-2)$ & $0.0078(1.3307)$ & VWROE & $0.0042(0.7178)$ \\
\hline VWROE(-1) & $-0.0140(-2.2612)^{*}$ & $\operatorname{INF}(-3)$ & $-0.0199(-3.4679)^{* *}$ & VWROE(-1) & $-0.0105(-1.9189)$ \\
\hline VEPS & $-0.0012(-1.1336)$ & MS & $0.0019(0.7556)$ & VEPS & $0.0000(0.2636)$ \\
\hline VEPS(-1) & $-0.0012(-1.1164)$ & EX & $0.0007(0.5680)$ & VWPTBV & $-0.0000(-0.0508)$ \\
\hline VWPTBV & $0.0003(0.3164)$ & $\mathrm{EX}(-1)$ & $-0.0004(-0.2929)$ & ATV & $0.0241(4.3828)^{* *}$ \\
\hline PYOUNG & $-0.0041(-0.7013)$ & $\mathrm{EX}(-2)$ & $0.0030(2.5058)^{*}$ & PYOUNG & $-0.0233(-2.2235)^{*}$ \\
\hline PYOUNG(-1) & $-0.0170(-2.5409)^{*}$ & VWROE & $-0.0006(-0.7805)$ & PYOUNG(-1) & $-0.0748(-5.3115)^{* *}$ \\
\hline ATV & $0.0144(0.4221)$ & VEPS & $-0.0002(-1.3941)$ & PYOUNG(-2) & $0.1003(9.0752)^{* *}$ \\
\hline $\operatorname{ATV}(-1)$ & $0.0651(1.7881)$ & VWPTBV & $0.0003(2.3295)^{*}$ & POL & $-0.0008(-0.1646)$ \\
\hline POL & $-0.0778(-3.4889)^{* *}$ & VWPTBV(-1) & $0.0005(1.7449)$ & Constant & $-0.0007(-0.1667)$ \\
\hline Constant & $0.0526(2.0963)$ & VWPTBV(-2) & $-0.0005(-2.5112)^{*}$ & Trend & $-0.0000(-0.0614)$ \\
\hline \multirow[t]{7}{*}{ Trend } & $0.0003(3.3547)^{* *}$ & PYOUNG & $0.0004(0.1032)$ & & \\
\hline & & ATV & $-0.0020(-0.2214)$ & & \\
\hline & & POL & $-0.0321(-2.6591)^{* *}$ & & \\
\hline & & POL $(-1)$ & $0.0179(1.6093)$ & & \\
\hline & & POL $(-2)$ & $0.0107(1.9075)$ & & \\
\hline & & Constant & $0.0061(2.2489)^{*}$ & & \\
\hline & & Trend & $-0.0000(-0.4649)$ & & \\
\hline Diagnostic tests & & Diagnostic test & & Diagnostic test & \\
\hline Adj. $R^{2}$ & 0.9803 & Adj. $\mathrm{R}^{2}$ & 0.9743 & Adj. $R^{2}$ & 0.9644 \\
\hline DW & 2.6100 & DW & 1.9745 & DW & 1.9943 \\
\hline $\mathrm{LM}(1)$ & $6.5463 *$ & $\operatorname{LM}(1)$ & 0.0313 & $\operatorname{LM}(1)$ & 0.0720 \\
\hline $\mathrm{LM}(2)$ & $13.8813^{* *}$ & $\mathrm{LM}(2)$ & 0.0376 & $\operatorname{LM}(2)$ & 1.0360 \\
\hline $\mathrm{LM}(3)$ & $23.5621^{* *}$ & $\operatorname{LM}(3)$ & 0.6140 & $\operatorname{LM}(3)$ & 5.9266 \\
\hline $\mathrm{ARCH}(1)$ & 0.0001 & $\mathrm{ARCH}(1)$ & $7.8159^{* *}$ & $\mathrm{ARCH}(1)$ & 1.3088 \\
\hline $\mathrm{ARCH}(2)$ & 0.0254 & $\mathrm{ARCH}(2)$ & $7.7730^{*}$ & $\mathrm{ARCH}(2)$ & 1.0328 \\
\hline $\mathrm{ARCH}(3)$ & 0.3899 & $\mathrm{ARCH}(3)$ & $20.9507 * *$ & $\mathrm{ARCH}(3)$ & 2.1384 \\
\hline
\end{tabular}

Notes: * denotes significance at $5 \%$ level. ** denotes significance at $1 \%$ level. Adj. $R^{2}$ is the adjusted $R^{2}$. DM is Durbin-Watson statistic. $\mathrm{LM}$ is the Lagrange multiplier test of disturbance term serial correlation. ARCH is the Lagrange multiplier test for autoregressive conditional 
Table 5: ARDL (Malaysia)

\begin{tabular}{|c|c|c|c|c|c|}
\hline \multicolumn{2}{|c|}{ Regime I: 1995:01-1997:12 } & \multicolumn{2}{|c|}{ Regime II: 1998:01-2008:06 } & \multicolumn{2}{|c|}{ Regime III: 2008:07-2018:12 } \\
\hline $\operatorname{MRV}(-1)$ & $-0.4060(-2.0280)$ & $\operatorname{MRV}(-1)$ & $0.6090(13.8215)^{* *}$ & $\operatorname{MRV}(-1)$ & $0.6516(6.7650)^{* *}$ \\
\hline GDP & $-0.1044(-2.7800)^{*}$ & GDP & $-0.0147(-2.3046)^{*}$ & $\operatorname{MRV}(-2)$ & $-0.2139(-1.5430)$ \\
\hline INT & $-0.0191(-0.8155)$ & INT & $-0.0139(-0.4493)$ & $\operatorname{MRV}(-3)$ & $0.2770(2.3996)^{*}$ \\
\hline $\operatorname{INT}(-1)$ & $-0.0652(-2.9056)^{*}$ & $\mathrm{INT}(-1)$ & $-0.0528(-2.0403)^{*}$ & GDP & $-0.0558(-2.0361)^{*}$ \\
\hline INF & $-0.1071(-1.6876)$ & $\mathrm{INT}(-2)$ & $0.1597(6.4126)^{* *}$ & $\operatorname{GDP}(-1)$ & $0.1121(2.2897)^{*}$ \\
\hline MS & $0.0106(1.5113)$ & INF & $-0.0205(-1.0989)$ & $\operatorname{GDP}(-2)$ & $-0.0692(-.7515)^{* *}$ \\
\hline EX & $-0.0803(-.7533)^{* *}$ & $\operatorname{INF}(-1)$ & $0.0432(1.9299)$ & INT & $-0.0254(-0.3704)$ \\
\hline $\mathrm{EX}(-1)$ & $-0.0154(-1.4802)$ & MS & $0.0014(0.4188)$ & $\operatorname{INT}(-1)$ & $0.2585(2.9478)^{* *}$ \\
\hline VWROE & $0.0130(0.8498)$ & $\operatorname{MS}(-1)$ & $0.0114(3.2619)^{* *}$ & INT(-2) & $-0.0883(-1.3826)$ \\
\hline VEPS & $-0.0013(-.2020)^{* *}$ & $\mathrm{EX}$ & $0.0108(2.4589)^{*}$ & INF & $-0.0321(-3.1010)^{* *}$ \\
\hline VWPTBV & $-0.0006(-0.5160)$ & $\mathrm{EX}(-1)$ & $-0.0136(-3.2876)^{* *}$ & $\operatorname{INF}(-1)$ & $0.0315(3.6441)^{* *}$ \\
\hline VWPTBV(-1) & $0.0063(7.8988)^{* *}$ & VWROE & $-0.0100(-0.9769)$ & MS & $0.0033(1.6056)$ \\
\hline PYOUNG & $-0.0266(-0.9404)$ & VWROE(-1) & $0.0028(0.2043)$ & $\mathrm{EX}$ & $0.0012(1.0813)$ \\
\hline ATV & $0.0286(2.0903)$ & VWROE(-2) & $0.0291(2.4131)^{*}$ & VWROE & $0.0062(1.0745)$ \\
\hline $\operatorname{ATV}(-1)$ & $0.0311(2.3058)^{*}$ & VWROE(-3) & $-0.0182(-1.9471)$ & VWROE(-1) & $0.0075(1.1388)$ \\
\hline POL & $-0.0531(-1.7130)$ & VEPS & $-0.0003(-1.7564)$ & VWROE(-2) & $-0.0132(-2.5612)^{*}$ \\
\hline $\operatorname{POL}(-1)$ & $-0.0910(-3.6551)^{* *}$ & VEPS(-1) & $0.0006(2.7057)^{* *}$ & VEPS & $-0.0004(-2.9285)^{* *}$ \\
\hline Constant & $0.1220(4.8742)^{* *}$ & VEPS(-2) & $-0.0012(-5.5709)^{* *}$ & VWPTBV & $-0.0002(-2.4551)^{*}$ \\
\hline \multirow[t]{13}{*}{ Trend } & $0.0003(2.3686)^{*}$ & VEPS(-3) & $0.0013(6.2660)^{* *}$ & PYOUNG & $0.0048(2.8023)^{* *}$ \\
\hline & & VWPTBV & $-0.0032(-5.5186)^{* *}$ & ATV & $0.0007(0.1682)$ \\
\hline & & VWPTBV(-1) & $0.0023(4.1905)^{* *}$ & $\operatorname{ATV}(-1)$ & $-0.0094(-2.3466)^{*}$ \\
\hline & & PYOUNG & $0.0029(0.3383)$ & $\operatorname{ATV}(-2)$ & $-0.0064(-1.7379)$ \\
\hline & & PYOUNG(-1) & $-0.0150(-1.4258)$ & POL & $-0.0007(-0.6465)$ \\
\hline & & PYOUNG(-2) & $-0.0050(-0.4789)$ & Constant & $-0.0026(-1.7666)$ \\
\hline & & PYOUNG(-3) & $0.0209(2.3453)^{*}$ & Trend & $-0.0000(-0.2626)$ \\
\hline & & ATV & $0.0087(1.0886)$ & & \\
\hline & & $\operatorname{ATV}(-1)$ & $-0.0133(-1.6334)$ & & \\
\hline & & POL & $-0.0323(-2.4880)^{*}$ & & \\
\hline & & $\operatorname{POL}(-1)$ & $0.0298(1.7715)$ & & \\
\hline & & $\operatorname{POL}(-2)$ & $-0.0294(-2.4206)^{*}$ & & \\
\hline & & Constant & $0.0216(3.7691)^{* *}$ & & \\
\hline $\begin{array}{l}\text { Diagnostic } \\
\text { tests }\end{array}$ & & $\begin{array}{l}\text { Trend } \\
\text { Diagnostic } \\
\text { tests }\end{array}$ & $0.0000(0.3539)$ & $\begin{array}{l}\text { Diagnostic } \\
\text { tests }\end{array}$ & \\
\hline Adj. $R^{2}$ & 0.9779 & Adj. $\mathrm{R}^{2}$ & 0.9866 & Adj. $\mathrm{R}^{2}$ & 0.8863 \\
\hline DW & 2.8587 & DW & 2.0565 & DW & 2.2135 \\
\hline $\operatorname{LM}(1)$ & $14.2999 * *$ & $\operatorname{LM}(1)$ & 0.1909 & $\mathrm{LM}(1)$ & $6.0272 *$ \\
\hline $\mathrm{LM}(2)$ & $15.1342 * *$ & $\operatorname{LM}(2)$ & $12.2355^{* *}$ & $\operatorname{LM}(2)$ & $8.7921 *$ \\
\hline $\operatorname{LM}(3)$ & $20.3084 * *$ & $\operatorname{LM}(3)$ & $12.3848 * *$ & $\operatorname{LM}(3)$ & $23.2439 * *$ \\
\hline $\mathrm{ARCH}(1)$ & 0.0661 & $\mathrm{ARCH}(1)$ & 0.0099 & $\mathrm{ARCH}(1)$ & 0.1916 \\
\hline $\mathrm{ARCH}(2)$ & 1.4888 & $\mathrm{ARCH}(2)$ & 1.8195 & $\mathrm{ARCH}(2)$ & 0.1977 \\
\hline $\mathrm{ARCH}(3)$ & 2.2910 & $\mathrm{ARCH}(3)$ & 1.7924 & $\mathrm{ARCH}(3)$ & 0.6827 \\
\hline
\end{tabular}


Table 6: ARDL (Philippines)

\begin{tabular}{|c|c|c|c|c|c|}
\hline \multicolumn{2}{|c|}{ Regime I: 1995:01-1997:12 } & \multicolumn{2}{|c|}{ Regime II: 1998:01-2008:06 } & \multicolumn{2}{|c|}{ Regime III: 2008:07-2018:12 } \\
\hline $\operatorname{MRV}(-1)$ & $0.7217(7.8016)^{* *}$ & $\operatorname{MRV}(-1)$ & $0.6643(7.0191)^{* *}$ & $\operatorname{MRV}(-1)$ & $0.6651(7.3069)^{* *}$ \\
\hline GDP & $-0.0082(-0.3197)$ & $\operatorname{MRV}(-2)$ & $0.1146(1.0476)$ & $\operatorname{MRV}(-2)$ & $-0.2119(-1.8694)$ \\
\hline INT & $-0.0035(-0.5299)$ & $\operatorname{MRV}(-3)$ & $-0.1482(-1.7900)$ & $\operatorname{MRV}(-3)$ & $0.2213(2.4688)^{*}$ \\
\hline INF & $-0.0405(-1.5596)$ & GDP & $-0.0642(-4.4609)^{* *}$ & GDP & $-0.1243(-3.6189)^{* *}$ \\
\hline $\operatorname{INF}(-1)$ & $0.0442(1.6727)$ & INT & $-0.0166(-1.0482)$ & $\operatorname{GDP}(-1)$ & $0.2499(3.0190)^{* *}$ \\
\hline MS & $0.0106(1.5744)$ & INT(-1) & $0.0959(4.5299)^{* *}$ & $\operatorname{GDP}(-2)$ & $-0.1871(-2.3514)^{*}$ \\
\hline EX & $0.0003(0.0841)$ & $\operatorname{INT}(-2)$ & $-0.0204(-0.9263)$ & $\operatorname{GDP}(-3)$ & $0.0639(2.0868)^{*}$ \\
\hline VWROE & $0.0243(2.3432)^{*}$ & INT(-3) & $-0.0283(-1.7273)$ & INT & $0.0462(3.7299)^{* *}$ \\
\hline VEPS & $-0.0004(-0.4024)$ & $\mathrm{INF}$ & $-0.0467(-4.4272)^{* *}$ & INF & $-0.0064(-1.3236)$ \\
\hline VWPTBV & $-0.0005(-1.2229)$ & MS & $0.0002(0.1167)$ & MS & $0.0046(1.9969)^{*}$ \\
\hline PYOUNG & $0.0114(0.9015)$ & $\mathrm{EX}$ & $0.0045(2.1112)^{*}$ & $\operatorname{MS}(-1)$ & $-0.0039(-1.6951)$ \\
\hline PYOUNG(-1) & $-0.0344(-2.8382)^{*}$ & VWROE & $0.0088(1.7396)$ & $\mathrm{EX}$ & $-0.0078(-3.7309)^{* *}$ \\
\hline ATV & $0.0109(2.7152)^{*}$ & VEPS & $0.0002(1.0456)$ & VWROE & $-0.0029(-1.4670)$ \\
\hline POL & $0.0039(0.5734)$ & VWPTBV & $-0.0002(-0.9055)$ & VEPS & $0.0002(2.1144)^{*}$ \\
\hline \multirow[t]{15}{*}{ POL(-1) } & $0.0074(0.8050)$ & VWPTBV(-1) & $-0.0001(-0.3396)$ & VEPS(-1) & $-0.0002(-1.6783)$ \\
\hline & & VWPTBV(-2) & $0.0004(2.1088)^{*}$ & VWPTBV & $-0.0000(-1.3290)$ \\
\hline & & VWPTBV(-3) & $0.0004(2.5021)^{*}$ & VWPTBV(-1) & $0.0000(0.8547)$ \\
\hline & & PYOUNG & $0.0078(1.1120)$ & VWPTBV(-2) & $0.0000(0.7721)$ \\
\hline & & PYOUNG(-1) & $0.0044(0.5650)$ & VWPTBV(-3) & $0.0001(2.5840)^{*}$ \\
\hline & & PYOUNG(-2) & $-0.0044(-0.6032)$ & PYOUNG & $0.0207(2.3420)^{*}$ \\
\hline & & PYOUNG(-3) & $-0.0192(-3.2929)^{* *}$ & ATV & $-0.0057(-1.6592)$ \\
\hline & & ATV & $-0.0087(-1.4413)$ & $\operatorname{ATV}(-1)$ & $-0.0016(-0.4065)$ \\
\hline & & $\operatorname{ATV}(-1)$ & $-0.0121(-1.9865)^{*}$ & $\operatorname{ATV}(-2)$ & $-0.0054(-1.5884)$ \\
\hline & & $\operatorname{ATV}(-2)$ & $0.0019(0.2891)$ & POL & $-0.0042(-1.1423)$ \\
\hline & & $\operatorname{ATV}(-3)$ & $0.0114(2.1911)^{*}$ & Constant & $0.0052(1.7813)$ \\
\hline & & POL & $0.0188(1.8389)$ & Trend & $-0.0000(-3.5195)^{* *}$ \\
\hline & & POL(-1) & $-0.0196(-1.7818)$ & & \\
\hline & & Constant & $0.0087(1.3357)$ & & \\
\hline & & Trend & $-0.0001(-2.7772)^{* *}$ & & \\
\hline Diagnostic tests & & Diagnostic test & & Diagnostic test & \\
\hline Adj. $R^{2}$ & 0.9089 & Adj. $\mathrm{R}^{2}$ & 0.9300 & Adj. $\mathrm{R}^{2}$ & 0.9530 \\
\hline DW & 2.6032 & DW & 1.8589 & DW & 2.1121 \\
\hline $\mathrm{LM}(1)$ & $8.4166^{* *}$ & $\operatorname{LM}(1)$ & 1.8144 & $\operatorname{LM}(1)$ & 3.2178 \\
\hline $\mathrm{LM}(2)$ & $8.4380^{*}$ & $\operatorname{LM}(2)$ & 2.5915 & $\operatorname{LM}(2)$ & 4.0533 \\
\hline LM(3) & $13.3146^{* *}$ & $\mathrm{LM}(3)$ & 4.0786 & $\mathrm{LM}(3)$ & 4.1507 \\
\hline $\mathrm{ARCH}(1)$ & 3.4631 & $\mathrm{ARCH}(1)$ & 0.0075 & ARCH(1) & $3.8443 *$ \\
\hline $\mathrm{ARCH}(2)$ & 0.9285 & $\mathrm{ARCH}(2)$ & 0.7024 & $\mathrm{ARCH}(2)$ & 4.2037 \\
\hline $\mathrm{ARCH}(3)$ & 4.7076 & $\mathrm{ARCH}(3)$ & 0.7321 & $\operatorname{ARCH}(3)$ & 4.3415 \\
\hline
\end{tabular}


Table 7: ARDL (Thailand)

\begin{tabular}{|c|c|c|c|c|c|}
\hline \multicolumn{2}{|c|}{ Regime I: 1995:01-1997:12 } & \multicolumn{2}{|c|}{ Regime II: 1998:01-2008:06 } & \multicolumn{2}{|c|}{ Regime III: 2008:07-2018:12 } \\
\hline $\operatorname{MRV}(-1)$ & $-0.7169(-3.2278)^{* *}$ & $\operatorname{MRV}(-1)$ & $0.5952(7.3360)^{* *}$ & $\operatorname{MRV}(-1)$ & $0.4974(5.0878)^{* *}$ \\
\hline GDP & $0.0144(0.7234)$ & $\operatorname{MRV}(-2)$ & $0.2477(3.0213)^{* *}$ & GDP & $0.0008(0.1854)$ \\
\hline INT & $0.0161(1.1552)$ & $\operatorname{MRV}(-3)$ & $-0.1470(-1.7106)$ & INT & $-0.0734(-0.5677)$ \\
\hline $\mathrm{INF}$ & $-0.1455(-2.5301)^{*}$ & GDP & $0.1168(2.1445)^{*}$ & INT(-1) & $-0.1440(-0.8120)$ \\
\hline $\operatorname{INF}(-1)$ & $0.1740(2.6739)^{*}$ & GDP(-1) & $-0.2626(-2.9332)^{* *}$ & INT(-2) & $0.6265(3.3921)^{* *}$ \\
\hline MS & $-0.0144(-2.1468)^{*}$ & $\operatorname{GDP}(-2)$ & $0.1620(3.1903)^{* *}$ & $\operatorname{INT}(-3)$ & $-0.2350(-2.2051)^{*}$ \\
\hline EX & $-0.0260(-2.4492)^{*}$ & INT & $0.0049(0.1359)$ & $\mathrm{INF}$ & $-0.0336(-3.3580)^{* *}$ \\
\hline VWROE & $0.1041(2.8508)^{*}$ & INT(-1) & $0.03667(0.8104)$ & MS & $0.0008(0.1894)$ \\
\hline VWROE(-1) & $-0.0589(-2.4990)^{*}$ & INT(-2) & $-0.1784(-4.2942)^{* *}$ & MS(-1) & $0.0055(1.1009)$ \\
\hline VEPS & $0.0026(3.8589)^{* *}$ & INT(-3) & $0.1475(5.9329)^{* *}$ & MS(-2) & $-0.0098(-2.2228)^{*}$ \\
\hline VEPS(-1) & $-0.0024(-3.8762)^{* *}$ & INF & $0.0238(1.6878)$ & $\mathrm{EX}$ & $-0.0004(-0.1030)$ \\
\hline VWPTBV & $-0.0015(-3.1836)^{* *}$ & MS & $-0.0057(-1.7716)$ & VWROE & $-0.0085(-1.0856)$ \\
\hline VWPTBV(-1) & $0.0019(3.7776)^{* *}$ & MS(-1) & $-0.0088(-2.4490)^{*}$ & VEPS & $0.0006(1.9427)$ \\
\hline PYOUNG & $0.0071(0.3734)$ & $\mathrm{EX}$ & $0.0036(0.8132)$ & VEPS(-1) & $-0.0005(-1.6068)$ \\
\hline PYOUNG(-1) & $0.0559(3.1435)^{* *}$ & $\mathrm{EX}(-1)$ & $-0.0154(-2.5180)^{*}$ & VWPTBV & $-0.0001(-1.1372)$ \\
\hline ATV & $-0.0324(-1.7253)$ & $\mathrm{EX}(-2)$ & $0.0091(2.1361)^{*}$ & PYOUNG & $0.0201(3.4974)^{* *}$ \\
\hline $\operatorname{ATV}(-1)$ & $0.0553(2.2636)^{*}$ & VWROE & $-0.0038(-0.6430)$ & ATV & $-0.0023(-0.8230)$ \\
\hline POL & $-0.0374(-2.2670)^{*}$ & VEPS & $-0.0002(-0.7669)$ & $\operatorname{ATV}(-1)$ & $0.0157(4.4127)^{* *}$ \\
\hline Constant & $-0.0060(-0.2849)$ & VEPS(-1) & $-0.0005(-2.3571)^{*}$ & $\operatorname{ATV}(-2)$ & $-0.0147(-5.0460)^{* *}$ \\
\hline \multirow[t]{16}{*}{ Trend } & $0.0010(5.5132)^{* *}$ & VEPS(-2) & $0.0010(4.3114)^{* *}$ & POL & $-0.0107(-1.3038)$ \\
\hline & & $\operatorname{VEPS}(-3)$ & $-0.0005(-2.7976)^{* *}$ & Constant & $0.0094(2.0770)^{*}$ \\
\hline & & VWPTBV & $0.0003(1.7122)$ & Trend & $-0.0000(-2.1481)^{*}$ \\
\hline & & VWPTBV(-1) & $-0.0003(-1.1914)$ & & \\
\hline & & VWPTBV(-2) & $0.0007(3.0623)^{* *}$ & & \\
\hline & & VWPTBV(-3) & $-0.0003(-1.7697)$ & & \\
\hline & & PYOUNG & $-0.0039(-0.3756)$ & & \\
\hline & & PYOUNG(-1) & $0.0204(1.5397)$ & & \\
\hline & & PYOUNG(-2) & $-0.0026(-0.1929)$ & & \\
\hline & & PYOUNG(-3) & $-0.0170(-1.5900)$ & & \\
\hline & & ATV & $0.0001(0.0288)$ & & \\
\hline & & $\operatorname{ATV}(-1)$ & $-0.0005(-0.1750)$ & & \\
\hline & & $\operatorname{ATV}(-2)$ & $0.0063(2.3801)^{*}$ & & \\
\hline & & POL & $0.0036(0.4464)$ & & \\
\hline & & Constant & $0.0053(0.7810)$ & & \\
\hline & & Trend & $-0.0000(-2.6189)^{*}$ & & \\
\hline Diagnostic tests & & Diagnostic tests & & Diagnostic & \\
\hline Adj. $R^{2}$ & 0.9835 & Adj. $R^{2}$ & 0.9775 & Adj. $R^{2}$ & 0.9203 \\
\hline DW & 2.5522 & DW & 2.0926 & DW & 1.9855 \\
\hline $\mathrm{LM}(1)$ & $4.4327^{*}$ & $\mathrm{LM}(1)$ & 0.6914 & $\mathrm{LM}(1)$ & 0.0063 \\
\hline $\mathrm{LM}(2)$ & $17.6149^{* *}$ & $\operatorname{LM}(2)$ & 3.9029 & $\operatorname{LM}(2)$ & $7.4297^{*}$ \\
\hline $\mathrm{LM}(3)$ & $21.3226^{* *}$ & $\operatorname{LM}(3)$ & 4.9924 & $\operatorname{LM}(3)$ & $10.2178^{*}$ \\
\hline $\mathrm{ARCH}(1)$ & 0.9802 & $\mathrm{ARCH}(1)$ & 1.1603 & $\mathrm{ARCH}(1)$ & 0.0027 \\
\hline $\mathrm{ARCH}(2)$ & 0.8065 & $\mathrm{ARCH}(2)$ & 3.9823 & $\mathrm{ARCH}(2)$ & $9.9625 * *$ \\
\hline $\operatorname{ARCH}(3)$ & 0.7301 & $\mathrm{ARCH}(3)$ & 5.5219 & $\mathrm{ARCH}(3)$ & $11.2919^{*}$ \\
\hline
\end{tabular}


Table 8: ARDL (Singapore)

\begin{tabular}{|c|c|c|c|c|c|}
\hline \multicolumn{2}{|c|}{ Regime I: 1995:01-1997:12 } & \multicolumn{2}{|c|}{ Regime II: 1998:01-2008:06 } & \multicolumn{2}{|c|}{ Regime III: 2008:07-2018:12 } \\
\hline $\operatorname{MRV}(-1)$ & $-0.2123(-1.9028)$ & $\operatorname{MRV}(-1)$ & $0.3978(4.9782)^{* *}$ & $\operatorname{MRV}(-1)$ & $0.7389(8.5743)^{* *}$ \\
\hline GDP & $0.0277(3.1778)^{* *}$ & $\operatorname{MRV}(-2)$ & $0.1630(2.0890)^{*}$ & $\operatorname{MRV}(-2)$ & $-0.2659(-2.5088)^{*}$ \\
\hline INT & $-0.0523(-1.9090)$ & GDP & $-0.0067(-0.9827)$ & GDP & $-0.0562(-2.3297)^{*}$ \\
\hline $\operatorname{INT}(-1)$ & $0.1383(5.5690)^{* *}$ & INT & $-0.0100(-3.5120)^{* *}$ & $\operatorname{GDP}(-1)$ & $0.1009(2.3908)^{*}$ \\
\hline $\mathrm{INF}$ & $-0.1092(-1.8469)$ & INT(-1) & $0.0668(1.8422)$ & GDP(-2) & $-0.0547(-2.3376)^{*}$ \\
\hline $\operatorname{INF}(-1)$ & $0.3285(4.1494)^{* *}$ & $\operatorname{INT}(-2)$ & $0.0828(2.4648)^{*}$ & INT & $-0.1247(-1.7373)$ \\
\hline MS & $-0.0217(-3.9022)^{* *}$ & INF & $0.0615(3.9616)^{* *}$ & INT(-1) & $0.0283(0.3828)$ \\
\hline EX & $-0.1059(-3.9734)^{* *}$ & MS & $-0.0103(-1.8718)$ & INT(-2) & $0.4331(6.0896)^{* *}$ \\
\hline $\mathrm{EX}(-1)$ & $-0.0805(-3.8568)^{* *}$ & MS(-1) & $-0.0080(-1.5326)$ & INT(-3) & $-0.1315(-1.7139)$ \\
\hline VWROE & $0.0431(0.9078)$ & EX & $-0.0454(-3.2211)^{* *}$ & INF & $0.0083(0.5581)$ \\
\hline VEPS & $0.0021(1.1519)$ & $\mathrm{EX}(-1)$ & $0.0310(2.0985)^{*}$ & MS & $-0.0033(-0.4917)$ \\
\hline VEPS(-1) & $-0.0020(-1.1610)$ & VWROE & $-0.0153(-4.3022)^{* *}$ & MS(-1) & $-0.0100(-1.3124)$ \\
\hline VWPTBV & $0.0000(0.0229)$ & VWROE(-1) & $0.0098(2.7705)^{* *}$ & MS(-2) & $0.0150(2.2885)^{*}$ \\
\hline VWPTBV(-1) & $0.0023(3.3911)^{* *}$ & VEPS & $-0.0001(-2.4340)^{*}$ & EX & $0.0027(0.1277)$ \\
\hline PYOUNG & $0.0342(2.6620)^{*}$ & VWPTBV & $-0.0037(-4.4548)^{* *}$ & $\mathrm{EX}(-1)$ & $-0.0695(-2.4487)^{*}$ \\
\hline ATV & $0.0042(0.3097)$ & VWPTBV(-1) & $0.0036(4.7253)^{* *}$ & $\mathrm{EX}(-2)$ & $0.0612(2.9043)^{* *}$ \\
\hline POL & $-0.0204(-1.0519)$ & PYOUNG & $0.0076(1.3783)$ & VWROE & $0.0052(0.6644)$ \\
\hline POL(-1) & $0.0426(2.2099)^{*}$ & ATV & $0.0192(2.6544)^{* *}$ & VEPS & $-0.0000(-0.4715)$ \\
\hline Constant & $-0.0439(-3.2773)^{* *}$ & POL & $0.0177(1.6231)$ & VEPS(-1) & $0.0000(0.3175)$ \\
\hline \multirow[t]{12}{*}{ Trend } & $0.0001(0.7835)$ & Constant & $-0.0150(-1.4320)$ & VEPS(-2) & $0.0001(1.4133)$ \\
\hline & & Trend & $0.0000(0.9280)$ & VEPS(-3) & $-0.0002(-2.7311)^{* *}$ \\
\hline & & & & VWPTBV & $-0.0007(-1.1209)$ \\
\hline & & & & PYOUNG & $0.0027(0.4435)$ \\
\hline & & & & PYOUNG(-1) & $0.0129(1.5347)$ \\
\hline & & & & PYOUNG(-2) & $-0.0162(-2.6191)^{*}$ \\
\hline & & & & ATV & $-0.0071(-0.8911)$ \\
\hline & & & & $\operatorname{ATV}(-1)$ & $0.0206(2.0806)^{*}$ \\
\hline & & & & $\operatorname{ATV}(-2)$ & $-0.0226(-2.6675)^{* *}$ \\
\hline & & & & POL & $0.0156(0.8399)$ \\
\hline & & & & Constant & $-0.0001(-0.0040)$ \\
\hline & & & & Trend & $-0.0000(-3.8009)^{* *}$ \\
\hline Diagnostic tests & & Diagnostic tests & & Diagnostic tests & \\
\hline Adj. $R^{2}$ & 0.9469 & Adj. $R^{2}$ & 0.9029 & Adj. $R^{2}$ & 0.8774 \\
\hline DW & 2.8313 & DW & 2.1372 & DW & 2.0843 \\
\hline $\mathrm{LM}(1)$ & $7.8509 * *$ & $\mathrm{LM}(1)$ & 2.1999 & $\operatorname{LM}(1)$ & 0.5820 \\
\hline $\mathrm{LM}(2)$ & $9.6179 * *$ & $\operatorname{LM}(2)$ & 3.3600 & $\operatorname{LM}(2)$ & 1.9302 \\
\hline $\mathrm{LM}(3)$ & $12.6837 * *$ & $\operatorname{LM}(3)$ & 3.3873 & $\operatorname{LM}(3)$ & $18.5474 * *$ \\
\hline $\mathrm{ARCH}(1)$ & 0.2349 & $\mathrm{ARCH}(1)$ & $5.6999 *$ & $\mathrm{ARCH}(1)$ & 0.0682 \\
\hline $\mathrm{ARCH}(2)$ & 0.9019 & $\mathrm{ARCH}(2)$ & $7.7739 *$ & $\mathrm{ARCH}(2)$ & 0.1802 \\
\hline $\mathrm{ARCH}(3)$ & 0.9409 & $\mathrm{ARCH}(3)$ & 7.6687 & $\mathrm{ARCH}(3)$ & $20.2116^{* *}$ \\
\hline
\end{tabular}


Table 9: Bounds Test for Co-Integration Analysis

\begin{tabular}{llllll}
\hline Time Period & Indonesia & Malaysia & Philippines & Thailand & Singapore \\
\hline Regime I: 1995:01-1997:11 & $5.4323^{* * *}$ & $16.2573 * * *$ & $3.3983^{*}$ & $9.8083^{* * *}$ & $18.3625^{* * *}$ \\
Regime II: 1998:01-2008:06 & $6.0774 * * *$ & $5.0904 * * *$ & $4.4658^{* * *}$ & $4.9591 * * *$ & $3.4782^{*}$ \\
Regime III: 2008:07-2018:12 & $4.1013 *$ & $3.5384 * *$ & $3.5796 * *$ & $5.2632^{*}$ & $5.0474 *$ \\
\hline
\end{tabular}

Notes: Critical values are cited from Narayan (2005): * Co-integration exists at $10, * * 5$, and $* * * 1$ per cent levels. 
Table 10: Pairwise Granger causality tests

\begin{tabular}{|c|c|c|c|c|c|c|c|c|c|c|c|c|c|c|c|}
\hline \multirow{2}{*}{ Null Hypothesis: } & \multicolumn{3}{|c|}{ Indonesia } & \multicolumn{3}{|c|}{ Malaysia } & \multicolumn{3}{|c|}{ Philippines } & \multicolumn{3}{|c|}{ Thailand } & \multicolumn{3}{|c|}{ Singapore } \\
\hline & 1 & $1-2$ & $1-3$ & 1 & $1-2$ & $1-3$ & 1 & $1-2$ & $1-3$ & 1 & $1-2$ & $1-3$ & 1 & $1-2$ & $1-3$ \\
\hline GDP dnc MRV & $4.890^{*}$ & $3.618^{*}$ & $5.243^{* *}$ & 1.503 & 0.443 & 0.410 & 1.334 & 0.420 & 1.042 & 0.000 & 0.171 & 0.415 & 0.537 & 0.594 & 0.253 \\
\hline MRV dnc GDP & 0.047 & $8.795^{* *}$ & 1.124 & $52.430 * *$ & $32.302 * *$ & $12.085 * *$ & $13.222 * *$ & $18.132 * *$ & $5.228 * *$ & 2.252 & $3.620 *$ & 1.547 & 3.270 & $4.317^{*}$ & $7.541 * *$ \\
\hline INT dnc MRV & $27.035^{* *}$ & $13.352 * *$ & $10.316^{* *}$ & $6.897^{*}$ & $5.562^{* *}$ & $7.755^{* *}$ & $7.661^{* *}$ & $3.935^{*}$ & 2.521 & $11.626^{* *}$ & $5.777^{* *}$ & $8.277 * *$ & 0.718 & $5.533 * *$ & $7.761 * *$ \\
\hline MRV dnc INT & 3.837 & $7.094 * *$ & $6.074 * *$ & $48.931 * *$ & $63.651 * *$ & $42.271 * *$ & 2.647 & 1.910 & 1.749 & $60.272 * *$ & $34.914 * *$ & $28.324 * *$ & 1.623 & 1.879 & $3.183 *$ \\
\hline INF dnc MRV & $11.329 * *$ & $7.580^{* *}$ & $6.414 * *$ & $15.463 * *$ & $7.145^{* *}$ & $5.300^{* *}$ & $7.878^{* *}$ & $3.852 *$ & $4.207 * *$ & $6.053 *$ & $8.001 * *$ & $5.814^{* *}$ & $5.626^{*}$ & 2.673 & 1.863 \\
\hline MRV dnc INF & 2.142 & 2.143 & $3.331^{*}$ & $9.586^{* *}$ & 1.019 & 0.790 & 1.490 & 0.329 & 1.395 & 3.822 & 0.889 & 0.258 & $5.794 *$ & $3.203^{*}$ & 2.518 \\
\hline MS dnc MRV & $11.414 * *$ & $5.610^{* *}$ & $3.784 *$ & 0.336 & 1.269 & 0.988 & 0.360 & 1.749 & 1.972 & 0.057 & 0.151 & 0.523 & 1.853 & $4.415^{*}$ & $3.794 *$ \\
\hline MRV dnc MS & 0.129 & 0.189 & 0.294 & 2.400 & 1.549 & 1.712 & 0.276 & 0.184 & 1.389 & 0.022 & 1.760 & 1.134 & 0.225 & 1.500 & 1.789 \\
\hline EX dnc MRV & $7.892 * *$ & $3.848^{*}$ & $3.349 *$ & 0.029 & 0.919 & 0.624 & 0.464 & $6.381 * *$ & $5.230 * *$ & 0.379 & 0.504 & 0.386 & 0.205 & $5.618^{* *}$ & $4.007 * *$ \\
\hline MRV dnc EX & 0.706 & 0.036 & 0.439 & 0.486 & 0.221 & 0.610 & 0.034 & 0.157 & 0.033 & 1.652 & 2.719 & 2.053 & 0.624 & 0.274 & 0.217 \\
\hline VWROE dnc MRV & $5.263 *$ & 2.565 & 1.728 & 2.240 & 2.293 & 1.503 & 2.747 & 1.163 & 1.200 & 0.053 & 0.119 & 0.079 & 0.197 & 0.560 & 0.317 \\
\hline MRV dnc VWROE & 0.096 & 0.474 & 0.428 & 0.059 & 0.114 & 0.088 & 3.453 & 1.995 & 1.457 & 0.490 & 0.263 & 0.520 & 1.191 & 1.417 & 1.339 \\
\hline VEPS dnc MRV & 0.140 & 0.090 & 0.072 & 0.183 & 0.098 & 0.193 & 0.404 & 0.183 & 0.654 & 2.636 & 1.062 & 0.902 & 0.356 & 0.090 & 0.998 \\
\hline MRV dnc VEPS & 0.049 & 0.023 & 0.073 & 0.004 & 0.260 & 0.253 & $4.651 *$ & 2.895 & 1.928 & $4.961 *$ & $3.986^{*}$ & $7.253^{* *}$ & $12.445 * *$ & $18.953 * *$ & $31.787 * *$ \\
\hline VWPTBV dnc MRV & 0.582 & 0.995 & 0.583 & 1.620 & 1.288 & 0.887 & 0.198 & 0.117 & 0.063 & $4.066^{*}$ & 2.691 & 1.768 & 1.064 & 0.765 & 0.688 \\
\hline MRV dnc VWPTBV & 0.929 & 1.451 & 2.558 & 0.532 & 0.470 & 0.459 & 0.865 & 0.520 & 0.491 & 0.002 & 0.035 & 0.033 & 1.989 & 1.973 & 1.612 \\
\hline PYOUNG dnc MRV & $5.469 *$ & $5.523 * *$ & $3.660^{*}$ & 0.000 & 0.000 & 0.003 & 0.369 & 0.473 & 0.200 & 3.190 & 2.187 & 1.434 & 0.104 & 0.913 & 1.465 \\
\hline MRV dnc PYOUNG & 0.441 & 0.548 & 0.333 & 0.011 & 0.069 & 0.099 & 3.461 & 2.239 & 2.486 & 2.197 & 2.179 & 1.583 & 0.408 & 0.337 & 0.372 \\
\hline ATV dnc MRV & 2.784 & 1.375 & 0.920 & 2.813 & 2.300 & 1.564 & 0.033 & 0.212 & 0.259 & $4.801 *$ & $11.084 * *$ & $9.836^{* *}$ & 0.313 & 1.260 & 0.779 \\
\hline MRV dnc ATV & $7.403 * *$ & $3.270^{*}$ & 1.327 & $5.549 *$ & 2.278 & 1.525 & 0.653 & 0.526 & 0.273 & 1.076 & $5.679 * *$ & $3.570 *$ & 0.043 & 0.450 & 0.280 \\
\hline POL dnc MRV & 0.282 & 0.113 & 1.457 & 0.494 & 0.226 & 0.250 & 0.344 & 0.282 & 0.437 & 1.713 & 1.428 & 2.136 & 1.070 & 1.268 & 0.736 \\
\hline MRV dnc POL & $11.869^{* *}$ & $7.441^{* *}$ & $4.837^{* *}$ & 0.056 & 0.129 & 0.168 & 0.216 & 0.205 & 0.187 & 0.224 & 0.165 & 0.358 & 1.234 & 0.544 & 0.403 \\
\hline
\end{tabular}

Notes: $\mathrm{dnc}=$ does not cause. ${ }^{*}$ denotes significance at $5 \%$ level. ${ }^{* *}$ denotes significance at $1 \%$ level. 
Table 11: Statistics of return volatility from the EGARCH, DCC-GARCH and PARCH: Robustness tests

\begin{tabular}{|c|c|c|c|c|c|c|c|c|c|c|}
\hline \multirow{2}{*}{ Country } & & \multicolumn{3}{|c|}{ EGARCH } & \multicolumn{3}{|c|}{ DCC-GARCH } & \multicolumn{3}{|c|}{ PARCH } \\
\hline & & Coefficient & Prob. & AIC & Coefficient & Prob. & AIC & Coefficient & Prob. & AIC \\
\hline \multirow[t]{4}{*}{ Indonesia } & $\square$ & -0.1162 & 0.0340 & 6.5363 & -0.1198 & 0.0279 & 6.5354 & 1.5296 & 0.7712 & 6.5388 \\
\hline & $\alpha$ & 0.2202 & 0.0028 & & 0.2189 & 0.0040 & & 0.0660 & 0.1835 & \\
\hline & $\gamma$ & -0.0160 & 0.7421 & & -0.0155 & 0.7539 & & -0.2375 & 0.0283 & \\
\hline & $\beta$ & 0.9870 & 0.0000 & & 0.9884 & 0.0000 & & 0.8755 & 0.0000 & \\
\hline \multirow[t]{4}{*}{ Malaysia } & $\square$ & -0.1451 & 0.0287 & 5.8584 & -0.1450 & 0.0283 & 5.8587 & 0.3246 & 0.3701 & 5.8621 \\
\hline & $\alpha$ & 0.2826 & 0.0008 & & 0.2822 & 0.0008 & & 0.1493 & 0.0195 & \\
\hline & $\gamma$ & -0.1037 & 0.0100 & & -0.1032 & 0.0101 & & 0.3002 & 0.0774 & \\
\hline & $\beta$ & 0.9750 & 0.0000 & & 0.9751 & 0.0000 & & 0.8389 & 0.0000 & \\
\hline \multirow[t]{4}{*}{ Philippines } & $\square$ & -0.0265 & 0.8067 & 6.5991 & -0.0338 & 0.7443 & 6.6014 & 0.4782 & 0.6105 & 6.6044 \\
\hline & $\alpha$ & 0.2034 & 0.0227 & & 0.1964 & 0.0245 & & 0.1069 & 0.0826 & \\
\hline & $\gamma$ & -0.0475 & 0.2885 & & -0.0460 & 0.2890 & & 0.2517 & 0.3574 & \\
\hline & $\beta$ & 0.9635 & 0.0000 & & 0.9671 & 0.0000 & & 0.8720 & 0.0000 & \\
\hline \multirow[t]{4}{*}{ Thailand } & $\square$ & -0.1210 & 0.1083 & 6.6506 & -0.1189 & 0.1020 & 6.6501 & 0.0165 & 0.3206 & 6.6374 \\
\hline & $\alpha$ & 0.2378 & 0.0057 & & 0.2281 & 0.0064 & & 0.0486 & 0.1218 & \\
\hline & $\gamma$ & -0.0557 & 0.1634 & & -0.0547 & 0.1607 & & 0.7924 & 0.0001 & \\
\hline & $\beta$ & 0.9822 & 0.0000 & & 0.9834 & 0.0000 & & 0.9354 & 0.0000 & \\
\hline \multirow[t]{4}{*}{ Singapore } & $\square$ & -0.0446 & 0.6282 & 6.1462 & -0.0520 & 0.5710 & 6.1461 & 0.5621 & 0.4904 & 6.1454 \\
\hline & $\alpha$ & 0.3101 & 0.0040 & & 0.3083 & 0.0042 & & 0.1675 & 0.0258 & \\
\hline & $\gamma$ & -0.1307 & 0.0229 & & -0.1334 & 0.0221 & & 0.4159 & 0.1181 & \\
\hline & $\beta$ & 0.9440 & 0.0000 & & 0.9468 & 0.0000 & & 0.8121 & 0.0000 & \\
\hline
\end{tabular}


Figure 1 (a, b, c): CUSUM and CUSUMSQ: Indonesia

Figure 1a: CUSUM and CUSUMSQ: Indonesia, Regime I

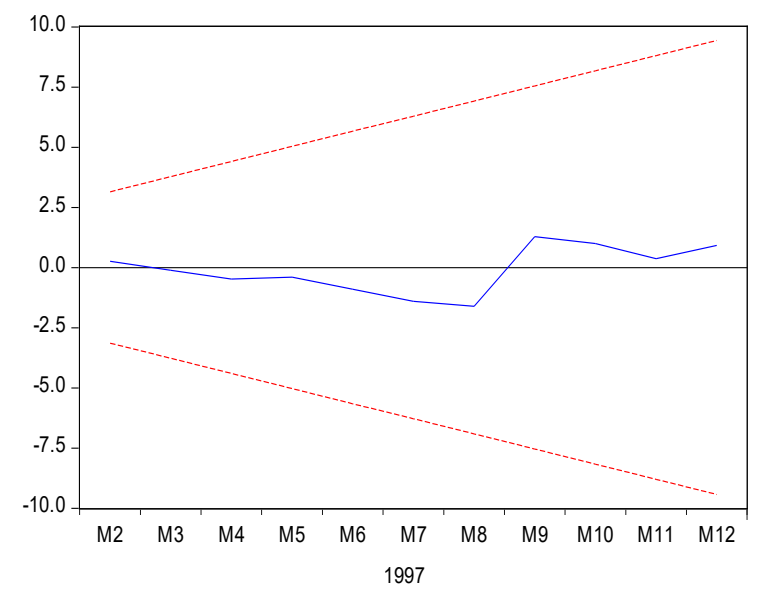

_ CUSUM ---. $5 \%$ Significance

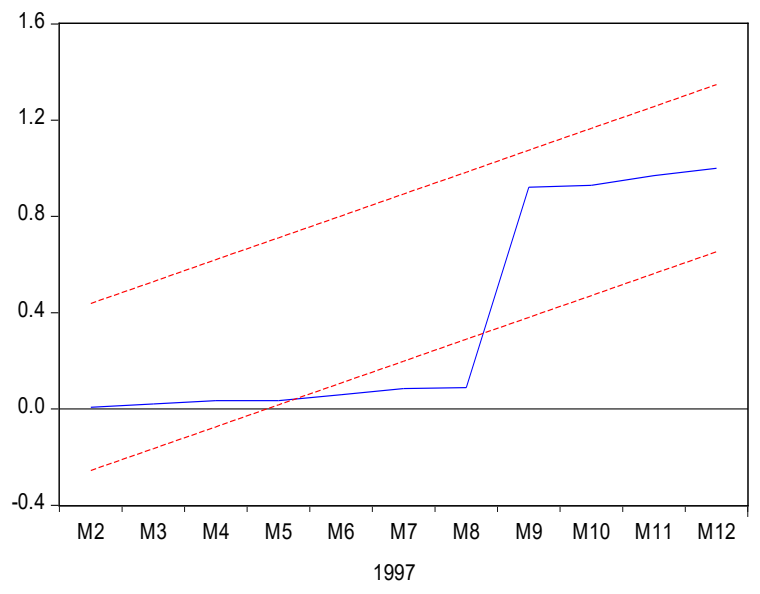

- CUSUM of Squares ---- $5 \%$ Significance

Figure 1b: CUSUM and CUSUMSQ: Indonesia, Regime II
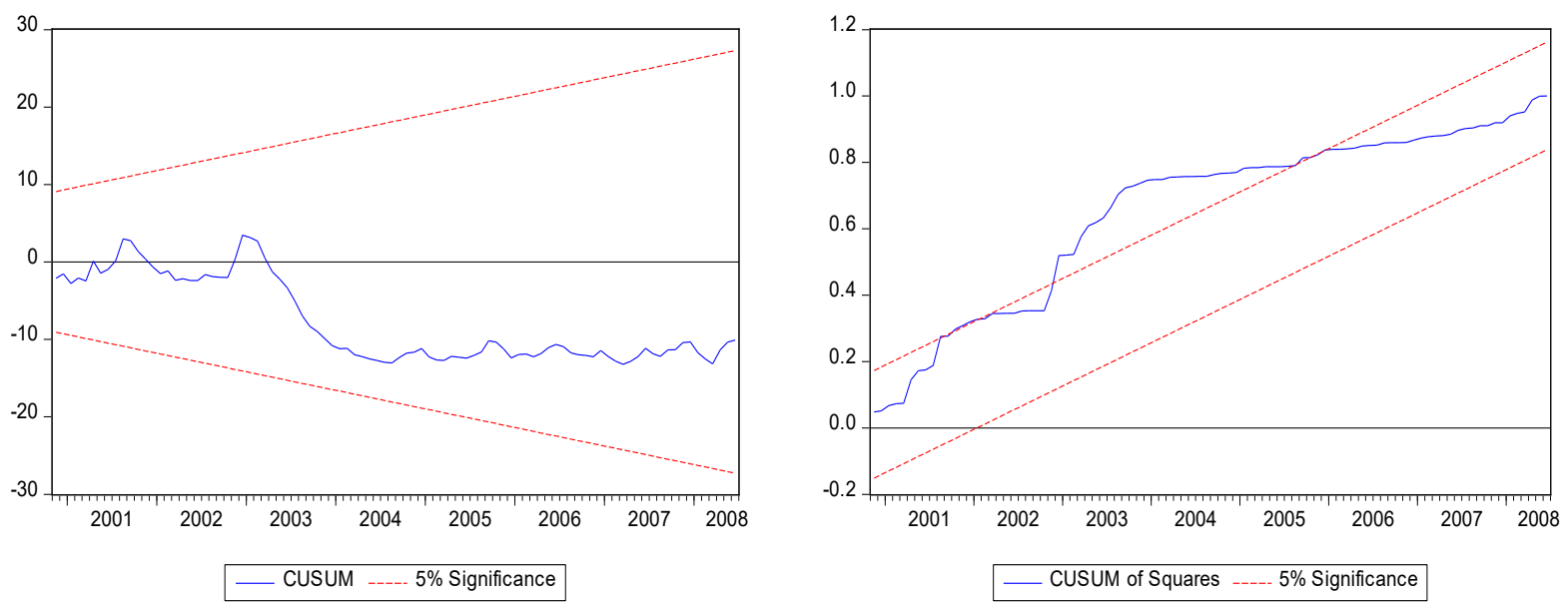

Figure 1c: CUSUM and CUSUMSQ: Indonesia, Regime III
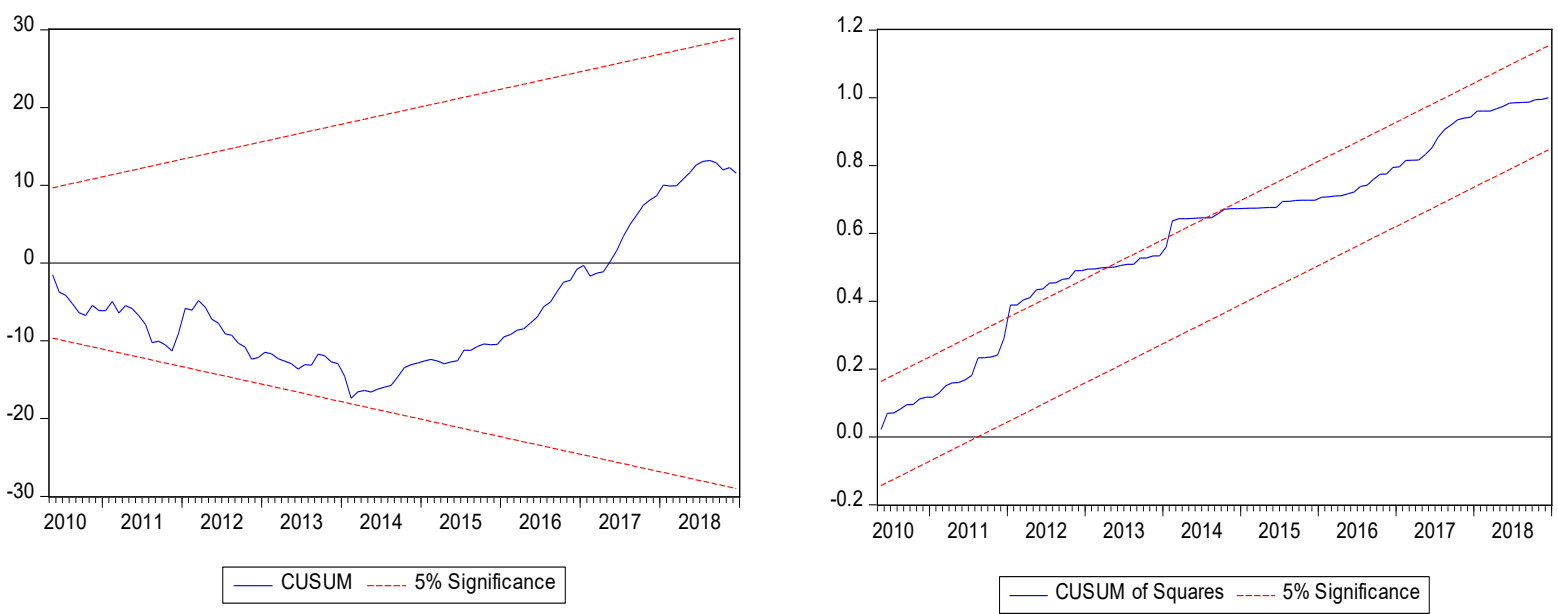
Figure 2 (a, b, c): CUSUM and CUSUMSQ: Malaysia

Figure 2a: CUSUM and CUSUMSQ: Malaysia, Regime I

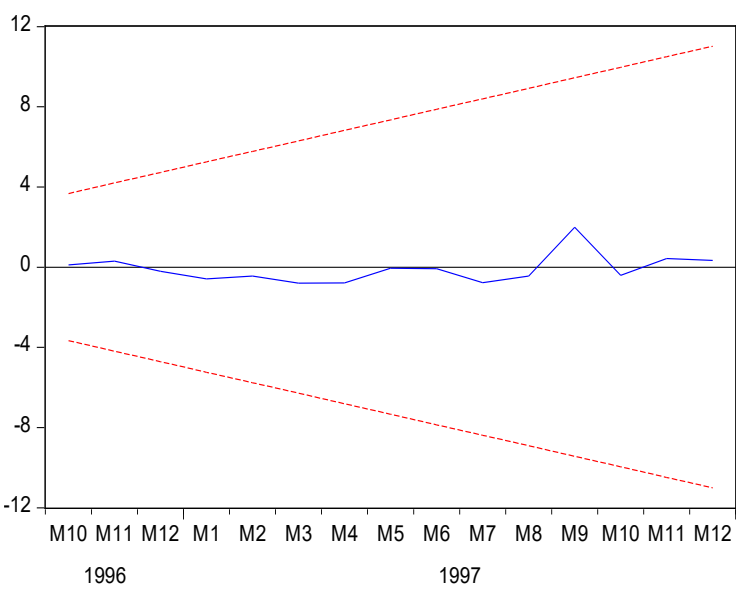

_ CUSUM ---- $5 \%$ Significance

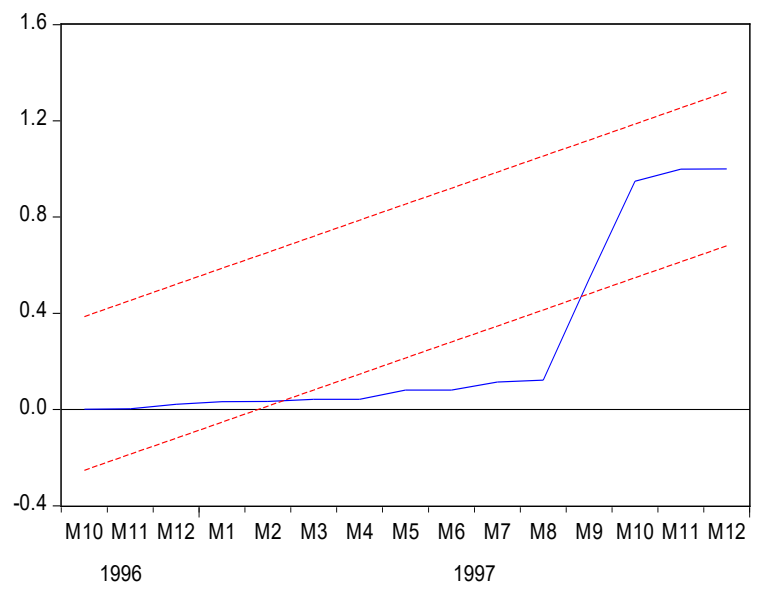

_ CUSUM of Squares ---- $5 \%$ Significance

Figure 2b: CUSUM and CUSUMSQ: Malaysia, Regime II
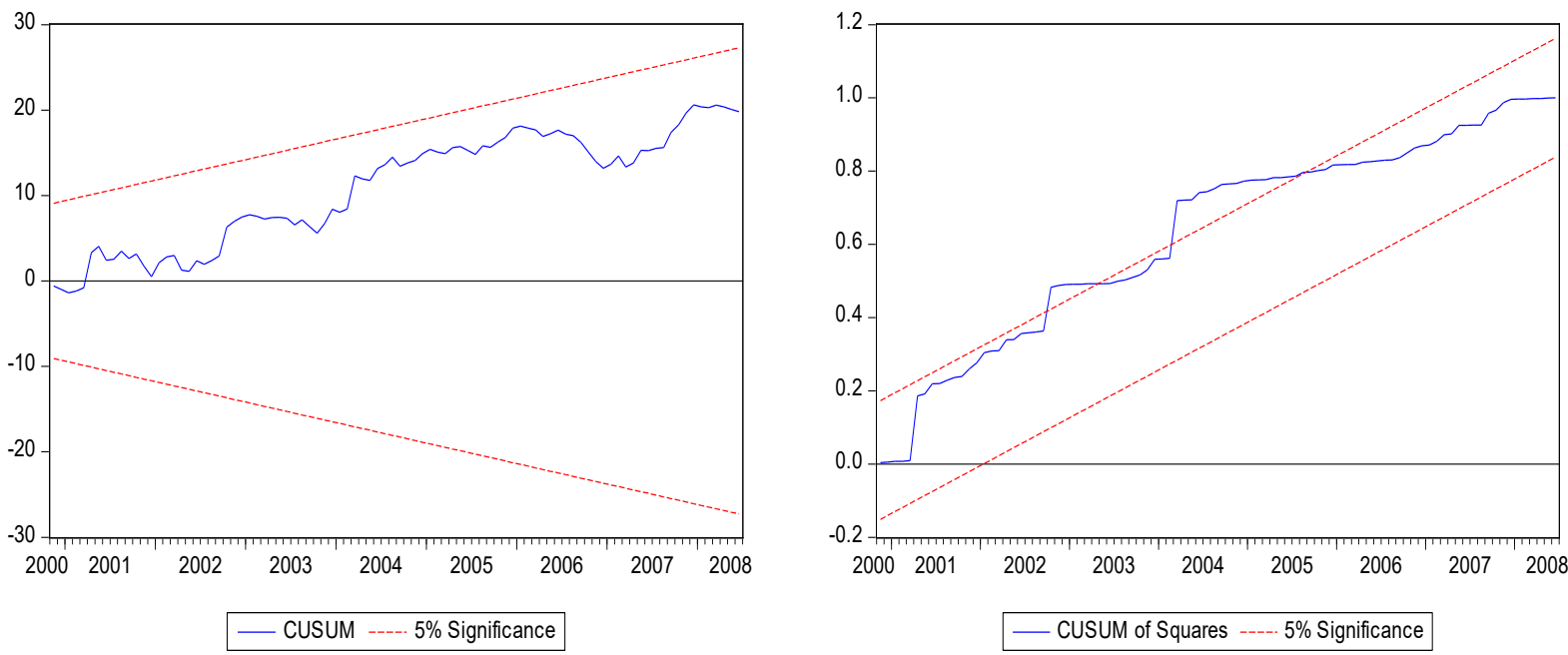

Figure 2c: CUSUM and CUSUMSQ: Malaysia, Regime III
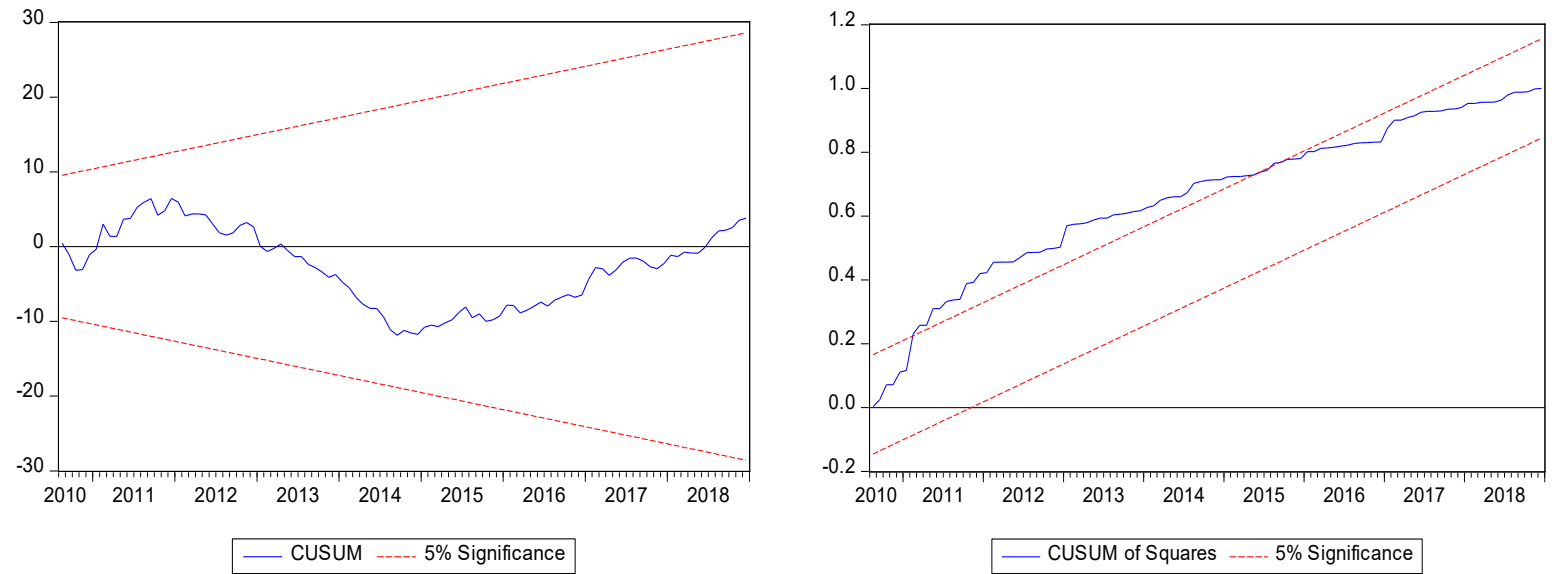
Figure 3 (a, b, c): CUSUM and CUSUMSQ: Philippines

Figure 3a: CUSUM and CUSUMSQ: Philippines, Regime I
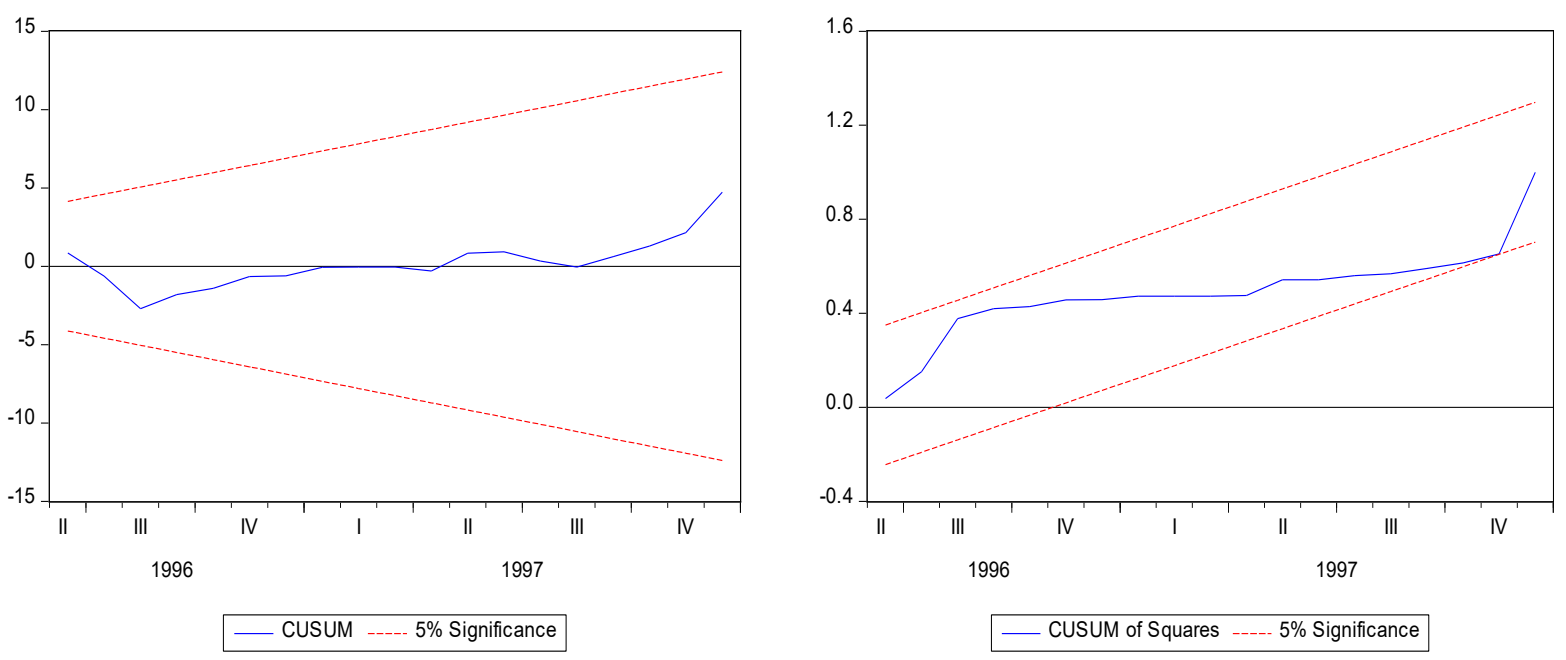

Figure 3b: CUSUM and CUSUMSQ: Philippines, Regime II
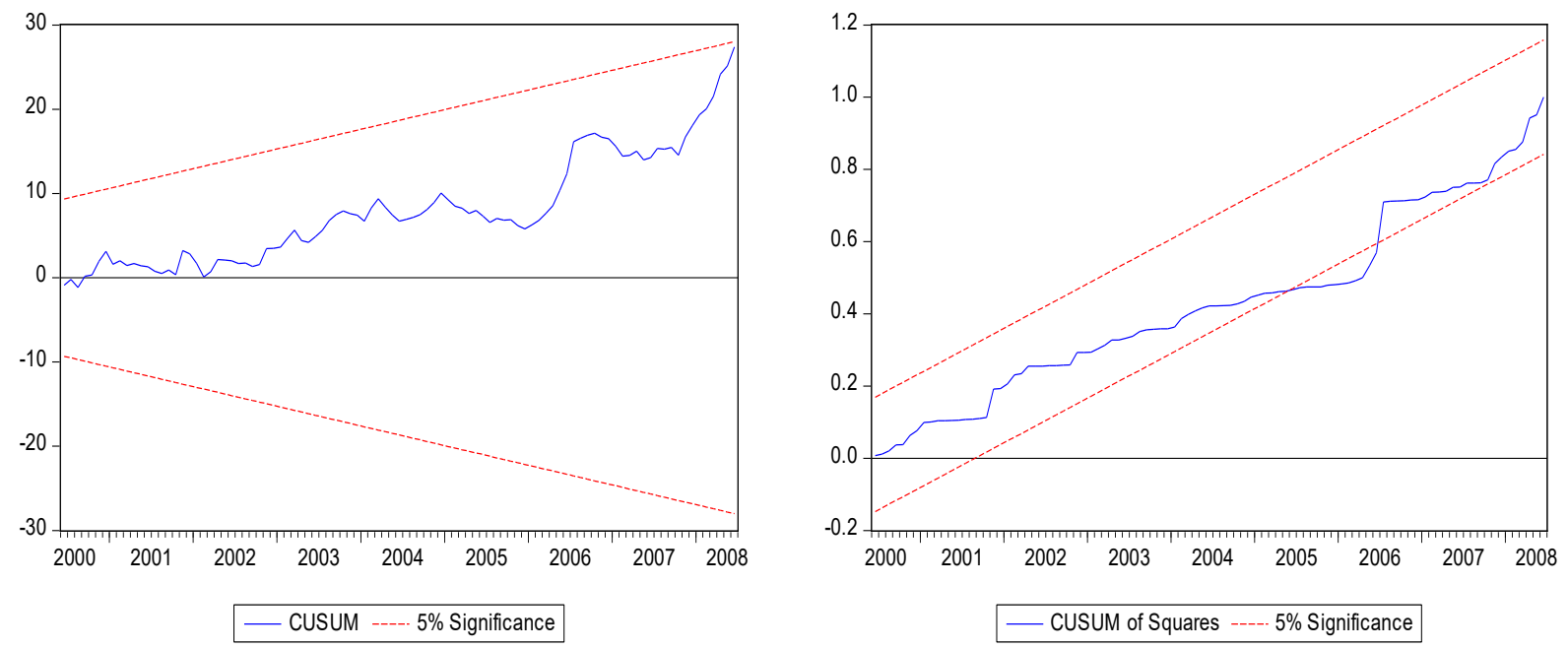

Figure 3c: CUSUM and CUSUMSQ: Philippines, Regime III
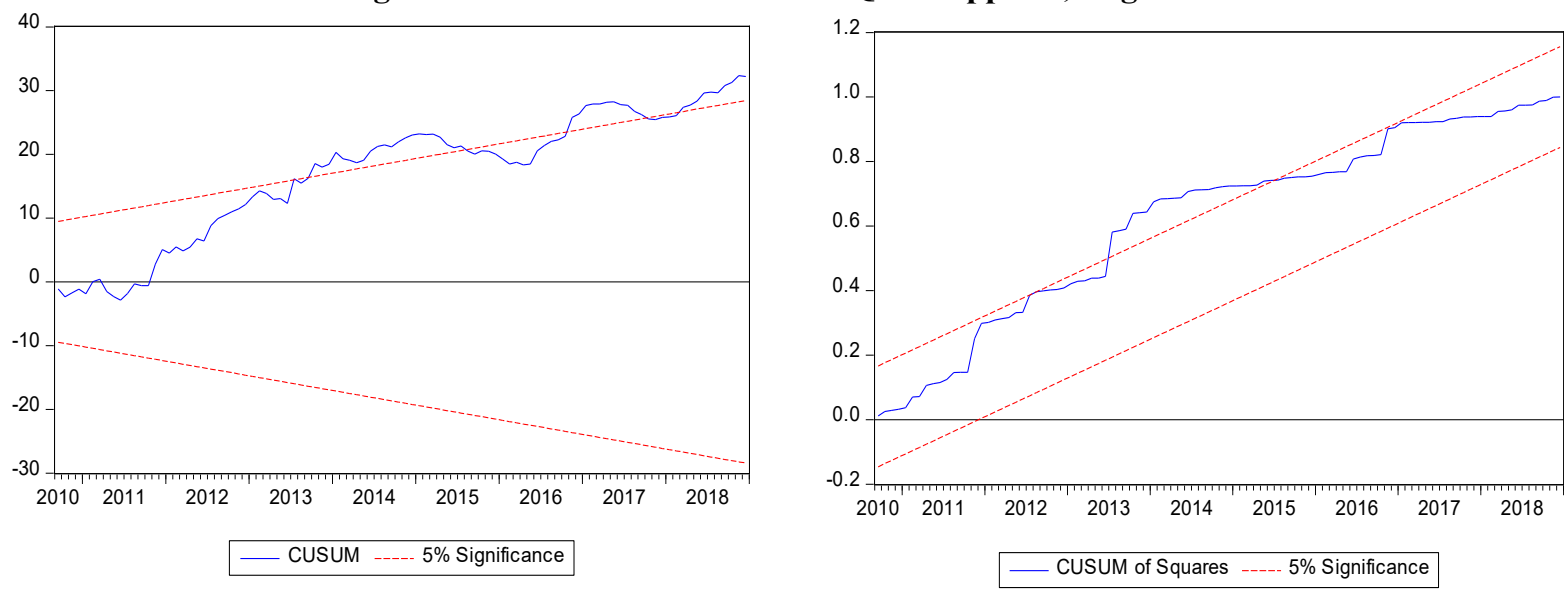
Figure 4 (a, b, c): CUSUM and CUSUMSQ: Thailand

Figure 4a: CUSUM and CUSUMSQ: Thailand, Regime I
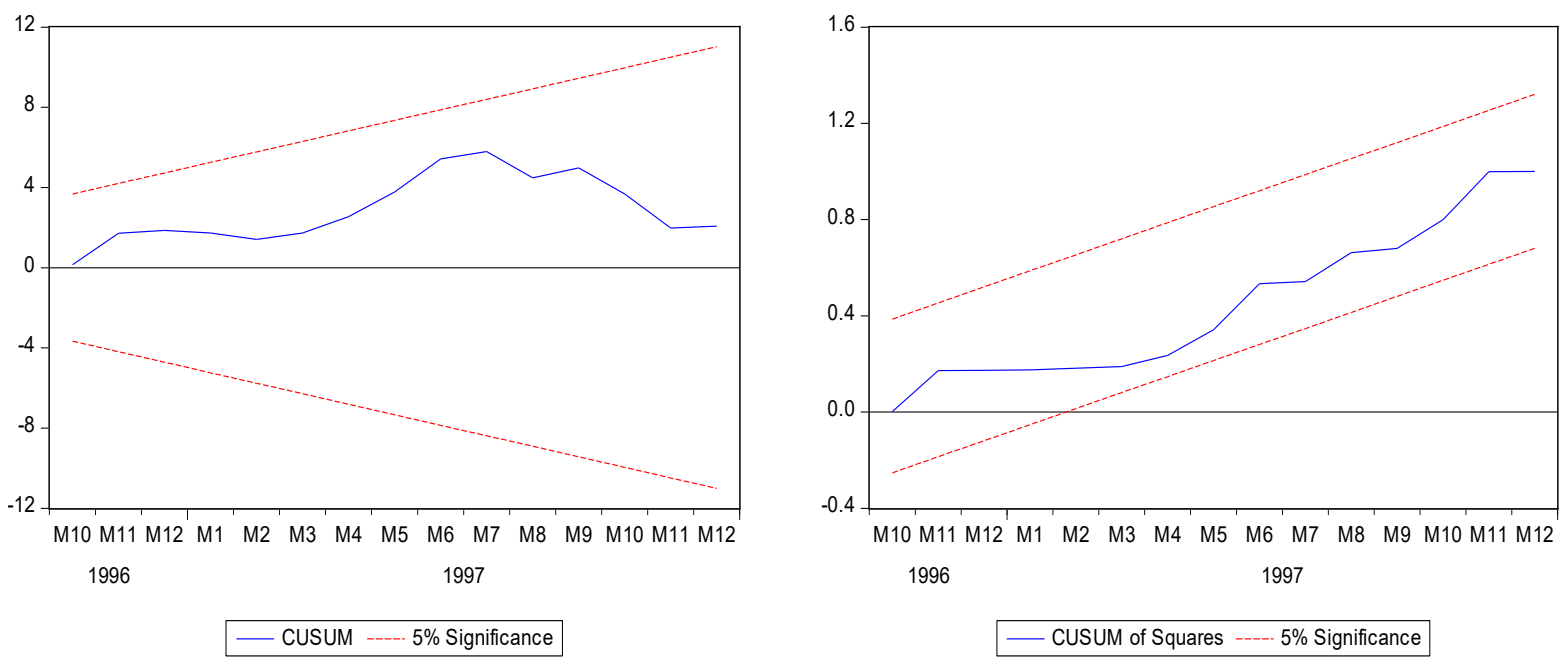

Figure 4b: CUSUM and CUSUMSQ: Thailand, Regime II
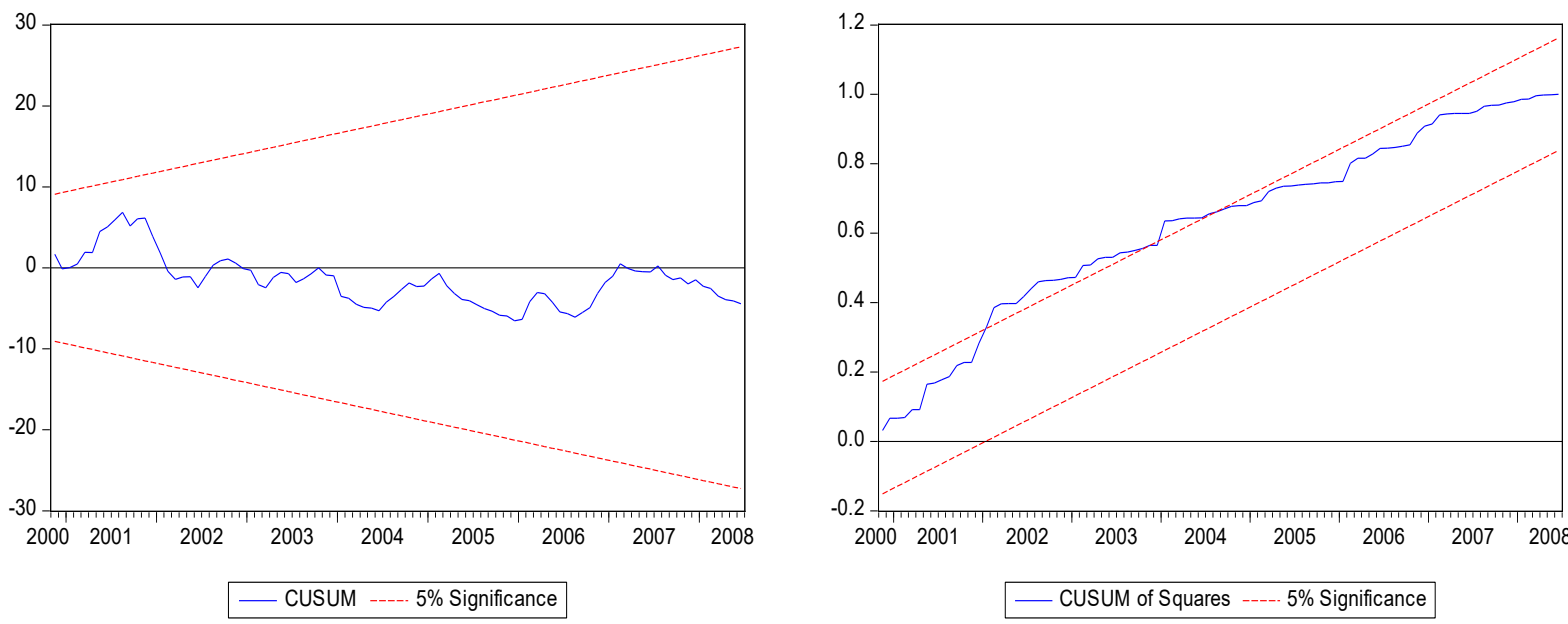

Figure 4c: CUSUM and CUSUMSQ: Thailand, Regime III
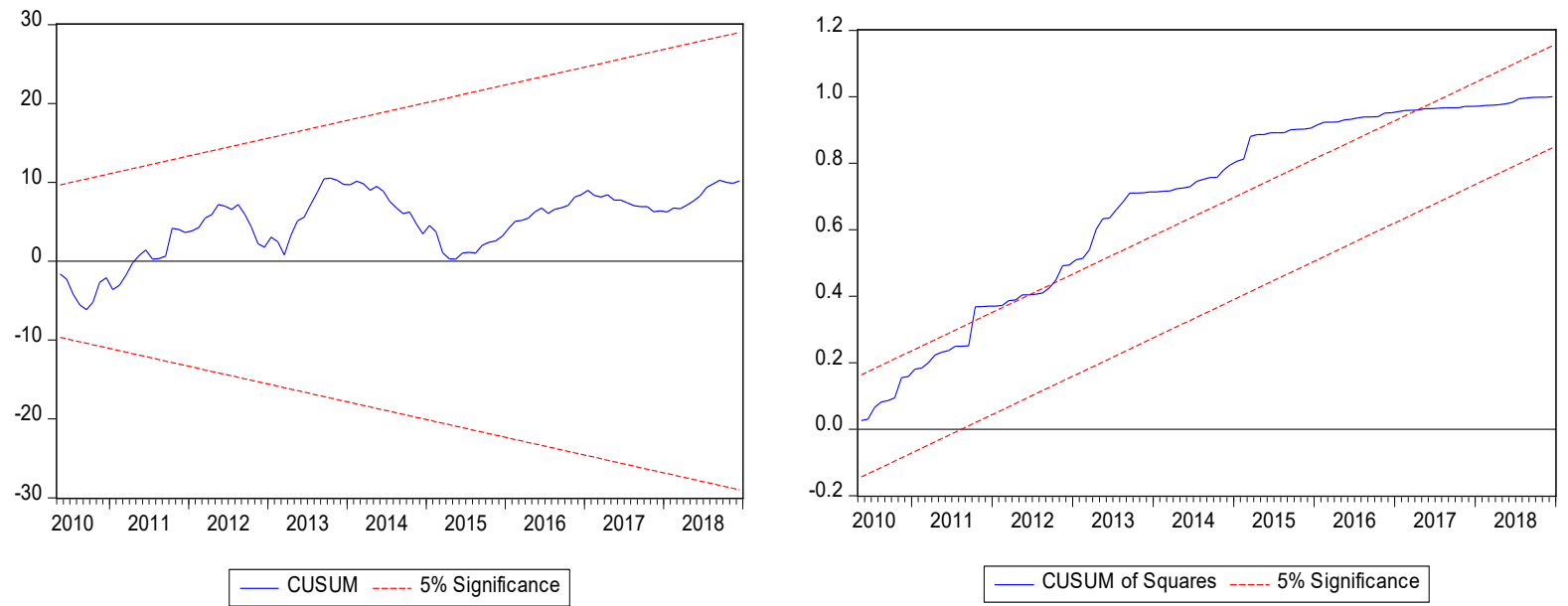
Figure 5 (a, b, c): CUSUM and CUSUMSQ: Singapore

Figure 5a: CUSUM and CUSUMSQ: Singapore, Regime I
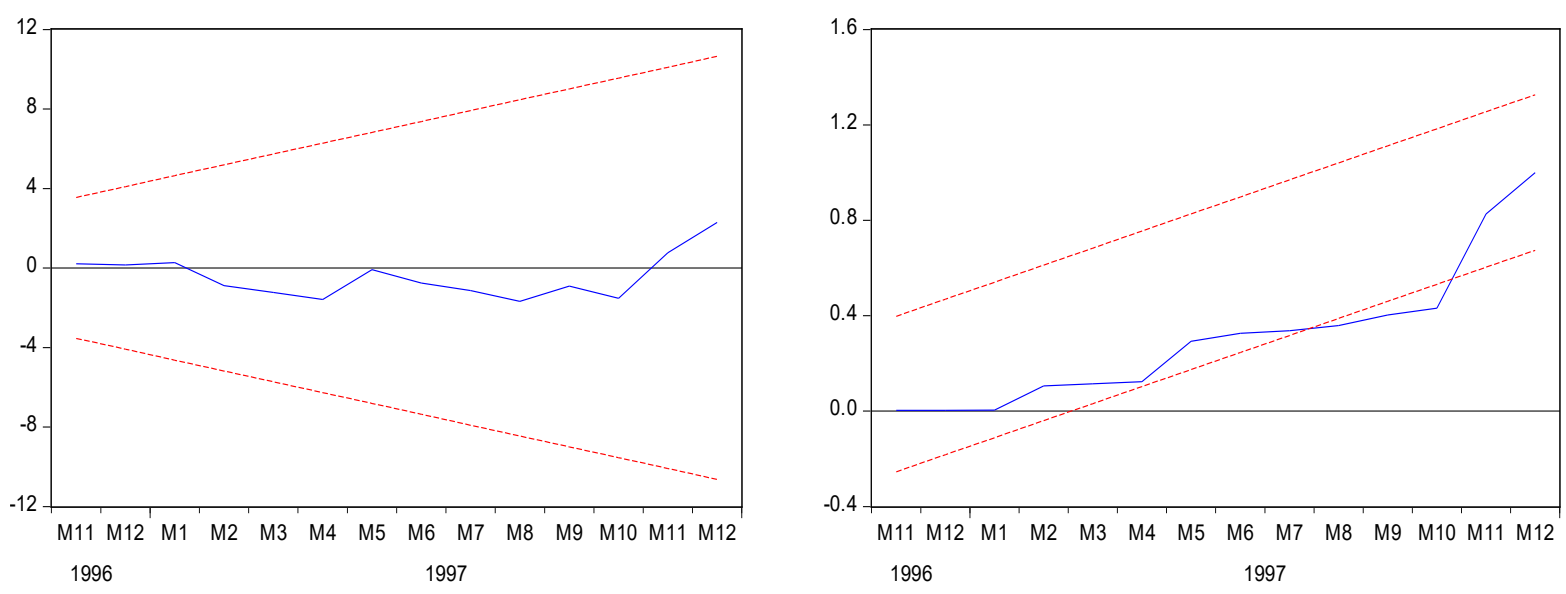

- CUSUM ---. $5 \%$ Significance

_ CUSUM of Squares ---- 5\% Significance

Figure 5b: CUSUM and CUSUMSQ: Singapore, Regime II
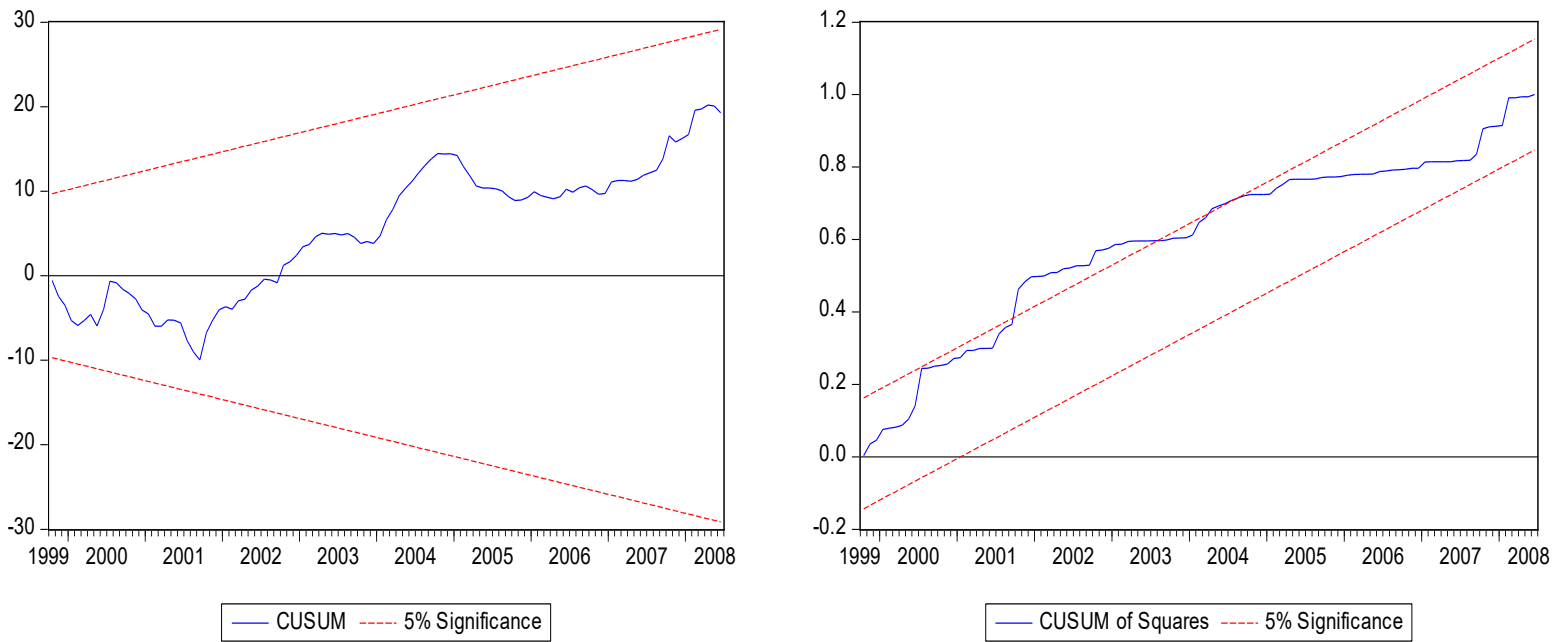

Figure 5c: CUSUM and CUSUMSQ: Singapore, Regime III
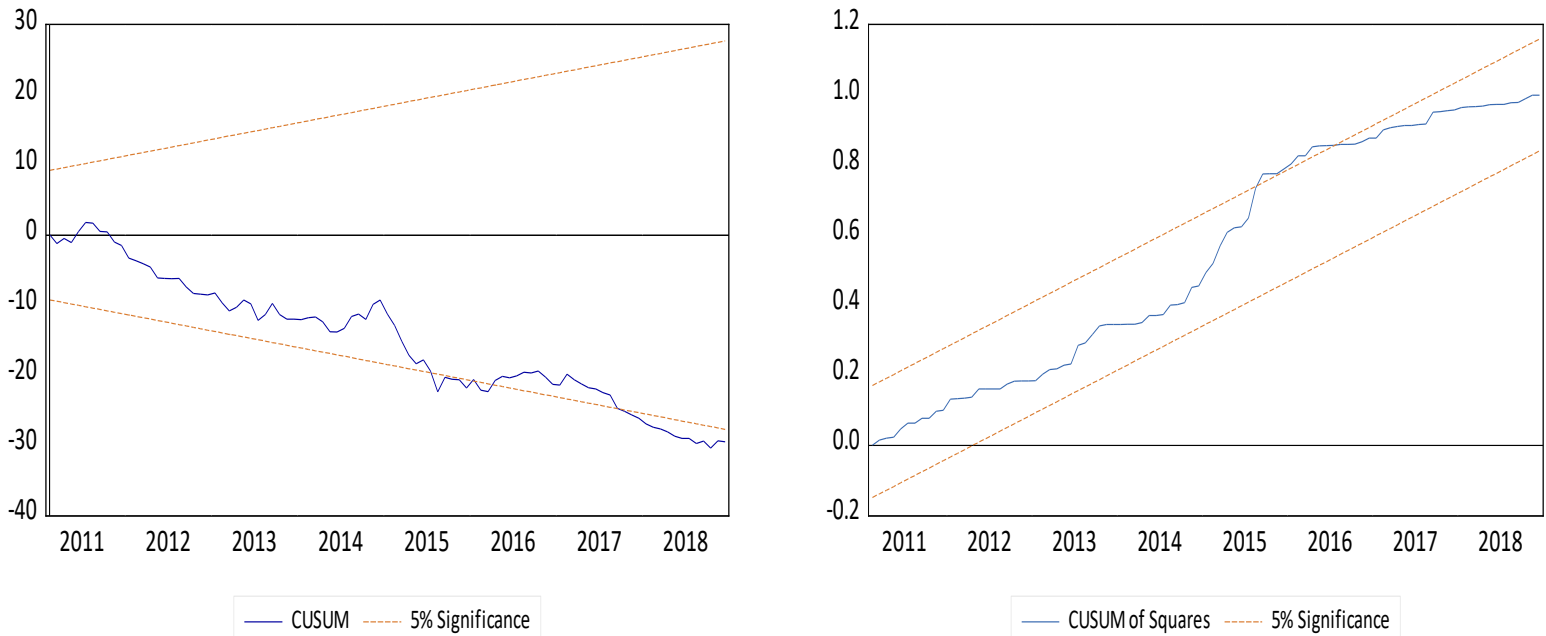
